2002-07-01

\title{
Regulation and measurement of oxidative stress in apoptosis
}

\author{
James Curtin \\ Technological University Dublin, james.curtin@tudublin.ie \\ Maryanne Donovan \\ University College Cork \\ Thomas Cotter \\ University College Cork
}

Follow this and additional works at: https://arrow.tudublin.ie/scschbioart

Part of the Biochemistry Commons

\section{Recommended Citation}

Curtin JF, Donovan M, Cotter TG. Regulation and measurement of oxidative stress in apoptosis. J Immunol Methods. 2002 Jul 1;265(1-2):49-72. Review. doi:10.21427/kd3y-r736

This Review is brought to you for free and open access by the School of Biological Sciences at ARROW@TU Dublin.

It has been accepted for inclusion in Articles by an authorized administrator of ARROW@TU Dublin. For more information, please contact arrow.admin@tudublin.ie, aisling.coyne@tudublin.ie,gerard.connolly@tudublin.ie. Funder: Irish Cancer Society, Fighting Blindness, HRB and Enterprise Ireland

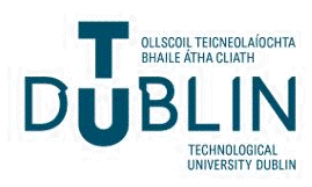




\title{
Regulation and measurement of oxidative stress in apoptosis
}

James F. Curtin ${ }^{1,+}$, Maryanne Donovan ${ }^{1}$ and Thomas G. Cotter

Tumour Biology Laboratory, Department of Biochemistry, Lee Maltings, University College Cork, Cork, Ireland

1 These authors contributed equally to this work.

† Current Address: School of Biological Sciences, Dublin Institute of Technology, Dublin 8, Ireland

Corresponding author. Tel.: +353-21-4904068; fax: +353-21-4904259; email: t.cotter@ucc.ie

\begin{abstract}
Cells are constantly generating reactive oxygen species (ROS) during aerobic metabolism. As a consequence, each cell is equipped with an extensive antioxidant defence system to combat excessive production of ROS. Oxidative stress occurs in cells when the generation of ROS overwhelms the cell's natural antioxidant defences. There is a growing consensus that oxidative stress and the redox state of a cell plays a pivotal role in regulating apoptosis, a tightly controlled form of cell death in which a cell partakes in its own demise. More recently, a role for reactive nitrogen species (RNI) as both positive and negative regulators of cell death has been established. This review describes the major sources of ROS and RNI in a cell, the control of cell death by these species and the role of antioxidants as regulators of oxidative stress and apoptosis. Finally, the various methods that can be employed in establishing a role for both ROS and RNI in apoptosis will be discussed with particular emphasis on their intracellular detection.
\end{abstract}

Author Keywords: Apoptosis; Reactive oxygen species; Nitric oxide; Oxidative stress; Antioxidants

Abbreviations: ROS, Reactive oxygen species; $\mathrm{O}^{-{ }^{-}}$, superoxide anion; $\mathrm{OH}$, hydroxyl radical; $\mathrm{H}_{2} \mathrm{O}_{2}$, hydrogen peroxide; $\mathrm{ER}$, endoplasmic reticulum; RNI, reactive nitrogen intermediates; NO, nitric oxide; NOS, nitric oxide synthase; $\mathrm{ONOO}^{-}$, peroxynitrite; NAC, $\mathrm{N}$-acetylcysteine; ETC, electron transport chain; TNF $\alpha$, tumour necrosis factor alpha; TNFR1, TNF receptor 1; SOD, superoxide dismutase; NGF, nerve growth factor; IL1R, interleukin 1 receptor; TCR, T cell receptor; IL1 $\beta$, interleukin 1B; cGMP, cyclic guanosine monophosphate; RSNO, nitrosothiol; CAD, caspase-activated DNAse; ICAD, inhibitor of caspase-activated DNAse; DTT, dithiothreitol; Ttg, tissue transglutamase; PTP, permeability transition pore; Gpx, glutathione peroxidase; GSH, glutathione; DCFH-DA, 2'-7'dichlorodihydrofluorescein diacetate; DCF, 2'-7'-dichlorofluorescein; DAF2-DA, 4,5-di aminofluorescein; L-NAME, NG-nitro-L-arginine methyl ester; L-NMMA, NG-methyl-L-arginine; 7-NI, 7-nitroindazole; L-NIO, N5-(1-iminoethyl)-L-ornithine; L-NIL, N5-(1-iminoethyl)-L-lysine; DPI, diphenylene iodonium; DDC, diethyldithiocarbamate; GST, glutathione-S-transferase

\section{Introduction}

Reactive oxygen species (ROS) are constantly generated under normal conditions as a consequence of aerobic metabolism. ROS include free radicals such as the superoxide anion $\left(\mathrm{O}^{-}{ }^{-}\right)$, hydroxyl radicals $(\mathrm{OH})$ and the nonradical hydrogen peroxide $\left(\mathrm{H}_{2} \mathrm{O}_{2}\right)$. They are particularly transient species 
due to their high chemical reactivity and can react with DNA, proteins, carbohydrates and lipids in a destructive manner. The cell is endowed with an extensive antioxidant defence system to combat ROS, either directly by interception or indirectly through reversal of oxidative damage. When ROS overcome the defence systems of the cell and redox homeostasis is altered, the result is oxidative stress.

Oxidative stress is implicated in the pathogenesis of several diseases including AIDS, Huntington's, Parkinson's disease, amyotrophic lateral sclerosis, Alzheimer's disease and retinal degenerative disorders. Evidently, the brain is particularly vulnerable. This is not surprising as the central nervous system is highly aerobic and thus extremely susceptible to oxidative stress. Additionally, the antioxidant defences of the brain are relatively low having almost no catalase and very low levels of glutathione (Slivka and Slivka).

The mitochondria are a major site of generation of free radicals. Under physiological conditions, electrons carried by the electron transport chain can leak out of the pathway and pass directly to oxygen, generating $\mathrm{O}_{2}{ }^{-}$. Other sources of $\mathrm{O}_{2}{ }^{-}$include enzymes such as cytochrome P450 in the endoplasmic reticulum (ER), lipoxygenases, cyclooxgenases, xanthine oxidase and NADPH oxidase. The dismutation of $\mathrm{O}_{2}{ }^{-}$by superoxide dismutase (SOD) results in the generation of $\mathrm{H}_{2} \mathrm{O}_{2}$, which can then react with $\mathrm{Fe}^{2+}$ to form hydroxyl radicals via the Fenton reaction:

$$
\mathrm{Fe}^{2+}+\mathrm{H}_{2} \mathrm{O}_{2} \rightarrow \mathrm{Fe}^{3+}+\mathrm{OH}+{ }^{-} \mathrm{OH}
$$

Hydroxyl radicals can also be generated via the metal catalysed Haber-Weiss reaction:

$$
\mathrm{O}_{2} \cdot{ }^{-}+\mathrm{H}_{2} \mathrm{O}_{2} \rightarrow \mathrm{O}_{2}+\mathrm{OH}+{ }^{-} \mathrm{OH}
$$

Reactive nitrogen intermediates (RNI) are now also recognised as important radicals. Nitric oxide (NO) is formed endogenously from the oxidation of $L$-arginine to $L$-citrulline by a family of NADPHdependent enzymes, the NO synthases. $\mathrm{NO}$ exists in different chemical forms ( $\mathrm{NO}^{-}, \mathrm{NO}$ and $\mathrm{NO}^{+}$) and thus has a wide-ranging degree of chemical reactivity and functions in a variety of different biological roles (Stamler et al., 1992). These include regulation of the cardiovascular system, smooth muscle relaxation, neurotransmission, coagulation and immune regulation. Despite these beneficial functions, the molecule has a pivotal role in cell death having the ability to both induce and protect against apoptosis as well as driving an apoptotic response into a necrotic one. NO can also combine with $\mathrm{O}_{2}{ }^{-}$to form peroxynitrite $\left(\mathrm{ONOO}^{-}\right)$, which shares some of NO's properties in that it too can diffuse freely intra- and intercellularly and also acts as a powerful oxidant.

It is now well established that the generation or addition of ROS or RNI can cause cell death either by apoptosis or necrosis, two distinct cell death pathways. Necrosis occurs usually in response to severe trauma/injury to the cell and is characterised morphologically by cytoplasmic and mitochondrial swelling, plasma membrane rupturing and release of the cellular contents into the extracellular space. Generation of an inflammatory response ensues, which can cause further injury or even death to neighbouring cells.

Apoptosis, by contrast, is a tightly regulated form of cell death in which a cell effectively partakes in its own demise. The execution of the death programme is characterised by morphological and biochemical changes. These include mitochondrial depolarisation and alterations in phospholipid asymmetry, chromatin condensation, nuclear fragmentation, membrane blebbing, cell shrinkage and 
the formation of membrane bound vesicles termed apoptotic bodies (Kerr et al., 1972). Many of the morphological changes associated with apoptosis are orchestrated by activation of a cascade of proteases termed caspases (Cohen and Porter). The caspases are a family of cysteine proteases comprising at least 14 members, all of which contain an active site thiol group necessary for activity (Thornberry and Lazebnik, 1998). This thiol group renders them particularly susceptible to redox modification by S-nitrosylation or oxidation. Such modifications result in the inhibition of their catalytic activities.

A role for oxidative stress in the induction of apoptosis is provided by studies where the addition of low levels of ROS induce apoptosis and the observation that various antioxidants such as $\mathrm{N}$ acetylcysteine (NAC) can inhibit cell death (Lennon and McGowan). Additionally, ROS generation has been reported to occur in TNF- and Fas-mediated apoptosis (Wolfe and Suzuki) as well as following treatment of cells with various agents including ultraviolet irradiation and chemotherapeutic drugs (Zamzami and Gorman). ROS and RNI are especially difficult to measure because of their very short half-lives. Early studies on oxidative stress and apoptosis were hampered by the lack of specific and sensitive detection methods with methods often restricted to the use of nonspecific probes. There now exists a wide range of techniques for detecting ROS and RNI in cells. While antioxidants and scavengers are effective tools for implicating ROS and RNI in apoptosis, a variety of probes permit the detection of ROS and RNI production both in living cells and in cell lysates. Specific inhibitors can be used to delineate the pathway at the source of ROS and RNI production. Here we will review the regulation of ROS and RNI, the major sources of oxidative stress, the role of natural antioxidants in controlling oxidative stress and the most commonly used techniques in the study of oxidative stress in apoptosis.

\section{Sources of ROS and RNI}

\subsection{Subcellular localisation of ROS/RNI production}

Both ROS and RNI can be generated at many different organelles in response to various stimuli. Major sources of ROS production include the mitochondrion, endoplasmic reticulum, plasma membrane and cytosol, while RNIs are usually formed in the cytosol or at the mitochondrion (Fig. 1).

The mitochondrion is the organelle in eukaryotes responsible for aerobic respiration and it is the most common source of ROS during apoptosis. In normal resting cells, $1-2 \%$ of electrons carried by the mitochondrial electron transport chain (ETC) leak from this pathway and form the superoxide free radical. Complex I, NADH-ubiquinone oxidoreductase and Complex III, ubiquinol-cytochrome c oxidoreductase are the two sites where superoxide is produced (Beyer, 1992). 02- generated by the cycling of ubiquinol in the inner mitochondrial membrane, is produced primarily in the mitochondrial matrix (Raha et al., 2000). High concentrations of the enzyme Mn-SOD in the mitochondrial matrix ensure that this basal level of superoxide production is neutralised before it can cause damage to the cell (Fig. 2).

Another oxidase gaining prominence in studies of apoptosis is NADPH oxidase, found the plasma membrane of phagocytes. Assembly and activation of this oxidase in response to a range of stimuli occurs during immune responses. Evidence is mounting that a similar, NADPH-like oxidase is expressed in a variety of cells throughout the body. Activation of this enzyme and subsequent superoxide production is necessary for apoptosis in a variety of systems (Finkel and Tammariello). 
NO is synthesised endogenously by a family of enzymes called nitric oxide synthases (NOS). Three major isoforms of this enzyme exist. While neuronal NOS (nNOS, NOS1) and endothelial NOS (eNOS, NOS3) are $\mathrm{Ca}^{2+} /$ calmodulin-dependent and constitutively expressed in a wide variety of cells, inducible NOS (iNOS, NOS2) is $\mathrm{Ca}^{2+}$ independent and is expressed in cells of the immune system and other cells in response to various stimuli (Nathan, 1997). The ability of some cells to regulate the expression of iNOS allows them to produce large amounts of nitric oxide on demand. nNOS, eNOS and iNOS are all present in the cytoplasm. The most recently discovered NOS, mitochondrial NOS (mtNOS), is present exclusively in the mitochondrion (Bates; Bates and Tatoyan). Co-stimulation of superoxide production and mtNOS can result in the formation of high concentrations of the highly reactive and damaging peroxynitrite (Packer and Bringold). All NOS enzymes function as homodimers. They generate nitric oxide (NO) by a two-step oxidation of the amino acid L-arginine to citrulline and NO via the intermediate compound N-hydroxy-L-arginine (NHA). Activation of NOS requires the binding of several co-factors, as reviewed by Groves and Wang (2000).

Many apoptotic signals generate ROS and RNI usually through the major sources outlined above. Receptors, the immune system, intracellular calcium, intracellular proteins, metabolic pathways and exogenously added chemicals are all capable of generating oxygen and nitrogen free radicals in a cell.

\subsection{Receptors}

Tumour necrosis factor alpha (TNF $\alpha$ ) is a pro-inflammatory cytokine that can bind to either TNF receptor 1 (TNFR1) or TNFR2. Binding of TNF $\alpha$ to TNFR1 usually results in caspase activation and apoptosis. It is well established that both ROS and RNI are generated by TNFa in many cell and tissue types. While ROS generation is not believed to be important in TNF-mediated apoptosis, generation of ROS by TNF $\alpha$ is critical for the phagocytic immune response against invading pathogens. (Woo et al., 2000).

RNIs play a key role in both inducing and inhibiting TNFa-mediated apoptosis. Binder and colleagues reported that NO generation was essential for TNF $\alpha$-mediated apoptosis. In this study, binding of TNF $\alpha$ to TNFR1 induced the expression of iNOS. Inhibition of iNOS activity abolished the cytotoxicity of TNF $\alpha$ in MCF7 and other TNF $\alpha$-susceptible cells (Binder et al., 1999). In a separate experiment, HeLa cells transfected with eNOS were found to be resistant to TNF $\alpha$-mediated apoptosis. The authors found that TNF $\alpha$ activated eNOS through ceramide formation. Generation of NO in this system was anti-apoptotic (Bulotta et al., 2001). These conflicting results highlight the dual effects that RNI and indeed ROS can have in different cells.

The Fas receptor is another member of the TNFR superfamily. Its natural ligand is the Fas ligand. Binding of Fas ligand to Fas receptor induces apoptosis by activating caspase 8 and caspase 3 . Detection of the rapid generation of ROS during Fas-mediated apoptosis has been reported and NADPH oxidase activation has been identified as the primary source of ROS production (Suzuki et al., 1998). The authors speculated that Fas activates a NADPH-like oxidase system in several cell types. However, the generation of ROS does not appear to be essential for Fas-mediated apoptosis in Jurkat T cells (Creagh and Cotter, 1999).

\subsection{Growth factors}


Growth factors are generally required for cell survival and cell proliferation in mammalian cells. The ability to proliferate independently of growth factors is one of the hallmarks of cancer. A noncancerous cell will die by apoptosis in the absence of growth factors.

Nerve growth factor (NGF) is essential for the survival of most neurons. Tammariello et al. (2000) studied ROS generation in NGF-deprived sympathetic neurons. They discovered that neuronal cells express NADPH oxidase. NGF withdrawal was found to activate this enzyme, and NADPH oxidasedeficient neurons are resistant to apoptosis induced by NGF withdrawal. ROS generation following growth factor withdrawal has also been documented for epidermal growth factor (EGF) (Lieberthal et al., 1998).

Growth factors are involved in angiogenesis (the growth of new blood vessels). Two of these, vascular endothelial growth factor (VEGF) and basic fibroblast growth factor (bFGF) are suspected of activating eNOS through the protein kinase Akt. It is believed that the antiapoptotic effects of NO may be required for VEGF-induced cell-cycle progression in vivo (Dimmeler et al., 1999).

\subsection{Immune system}

ROS/RNI generation plays an important role in the immune system. Phagocytes, including macrophages and neutrophils, are capable of generating large quantities of RNI and ROS, respectively. These free radicals are important for phagocytic anti-microbial and tumouricidal immune responses. It has been reported that NO generation is necessary for macrophage-induced apoptosis in at least some tumour cells (Cui et al., 1994).

Neutrophils have a short lifespan, usually about $24 \mathrm{~h}$ and ROSs appear to play an important role in neutrophil survival (Kasahara et al., 1997). Activated neutrophils undergo spontaneous apoptosis shortly after producing an ROS burst against invading pathogens. Research suggests that this spontaneous apoptosis is mediated by endogenous ROS production (Lundqvist-Gustafsson and Bengtsson, 1999). Survival of neutrophils incubated with antioxidants is greatly enhanced over $24 \mathrm{~h}$ in culture (Oishi and Machida, 1997).

Cytokines are a diverse family of extracellular signaling proteins produced by cells. Growth factors, such as NGF and EGF, are members of the cytokine superfamily. We have already discussed how these cells mediate survival through altering the cellular redox state. Here we consider two cytokine receptors present on immune cells, interleukin 1 receptor (IL1R) and T cell receptor (TCR).

Unlike NGF and EGF, interleukin $1 \beta$ (IL1 $\beta$ ) and TCR are pro-apoptotic. Apoptosis in astrocytes mediated by IL1 $\beta$ is associated with NO production. Inhibition of NOS can partially inhibit apoptosis in this system (Ehrlich et al., 1999). Pancreatic islet beta cells, however, require binding of both IL1 $\beta$ and IFN $\gamma$ with their respective receptors to induce iNOS expression and NO generation (Dupraz et al., 2000).

NOS also plays a role in TCR-mediated apoptotic death. In the thymus, stimulation of TCR results in the deletion of CD4, CD8 double-positive thymocytes. Expression of iNOS and subsequent NO generation is the primary pathway responsible for this process (Tai et al., 1997).

\subsection{Metabolic pathways and ROS}


Metabolic pathways may also play a role in ROS/RNI generation. Certain endogenous and exogenous compounds undergo enzymatic reactions yielding free radical species such as superoxide and nitric oxide. Proline, an amino acid, is one such compound. p53-dependent initiation of apoptosis involves up-regulation of proline oxidase activity. The reducing potential of proline oxidase is transferred to the ETC through the mediator cytochrome $c$. This extra reducing potential in the ETC supports the generation of ROS (Donald et al., 2001).

Arachidonic acid is a lipid precursor to leukotrienes and prostaglandins. Under certain conditions, metabolism of arachidonic acid generates ROS (Cadenas et al., 1983). Arachidonic acid administered to human retinoblastoma $Y 79$ cells induces apoptosis and the antioxidant glutathione can rescue these cells from apoptosis (Vento et al., 2000).

Many exogenously added chemicals induce ROS formation in cells and tissues. Some, such as MPTP in dopaminergic neurons, can produce free radicals directly without the need for enzymes. Most, however, require enzymatic reactions. Cytochrome P450 is a superfamily of enzymes responsible for detoxifying exogenous compounds. Some isoforms such as CYP3A are notorious ROS producers. Cyclosporin A, an immunosuppressant, is metabolised by CYP3A and produces large quantities of toxic ROS (Nguyen et al., 1999).

\section{Regulation of apoptosis by ROS}

The redox status of a cell can have obscure and elaborate effects on apoptosis. While addition of exogenous ROS is sufficient to trigger the apoptotic cascade, the executioners of apoptosis, for instance the caspases, are extremely sensitive to redox alterations and require a reducing environment in which to function. Perhaps one of the most potent regulators of apoptosis is NO, having the unique ability to both induce and block cell death. Anti-apoptotic effects of NO are associated with low levels $(10 \mathrm{~nm}-1 \mu \mathrm{m})$ of exposure from the activation of endogenous NOS and from the slow release of NO from NO donors. In addition, inhibition of apoptosis by NO can switch apoptotic cell death to necrosis in systems where NO may be acting below the point of no return. In these systems, inactivation of the execution machinery is not sufficient to prevent cell death and cells eventually die by necrosis. The outcome depends on several factors including cell type, the level of stress, redox state, the chemical form of NO and the ability of the cell to scavenge and detoxify ROS.

NO either delivered by NO donors or endogenously produced by NOS enzymes induces apoptosis both in vivo (Nishikawa and Donovan) and in several cell types in vitro, such as neuronal cells (Wei et al., 2000), macrophages (D'Acquisto et al., 2001), cardiac myocytes (Andreka et al., 2001), endothelial cells (Shen et al., 1998), lymphocytes and thymocytes (Okuda and Zhou). The mechanisms of NO-induced apoptosis are presently under intensive investigation and several mechanisms underlying the effects of NO on apoptosis have now been elucidated. These include activation of the death receptor Fas through upregulation of Fas ligand expression (Stassi et al., 1997), generation of peroxynitrite (Lin et al., 1995), inhibition of mitochondrial ATP synthesis (Almeida and Bolanos, 2001) and inactivation of several antioxidant enzymes (Asahi and Dobashi). In addition, NO activation of guanylate cyclase and resultant increases in intracellular calcium through cGMP-gated channels has also been demonstrated as a mechanism of NO-induced apoptosis in retinal cells in vivo (Donovan et al., 2001) (Fig. 3). 
NO has been reported to have protective effects against apoptosis in a variety of cell types including lymphocytes (Mannick; Mannick and Melino), hepatocytes (Li and Billiar, 1999), endothelial cells (Dimmeler and Rossig), neurons (Estevez et al., 1998) and eosinophils (Hebestreit et al., 1998). Several mechanisms have been proposed to elucidate the ability of NO to confer protection against cell death. These can be divided into cGMP-dependent and cGMP-independent mechanisms.

\section{1. cGMP dependent mechanisms}

NO can stimulate cGMP production through the activation of soluble guanylyl cyclase. NO dependent generation of intracellular cGMP has been shown to protect against apoptosis in lymphocytes (Genaro et al., 1995), eosinophils (Beauvais et al., 1995), embryonic motor neurons (Estevez et al., 1998), PC12 cells (Kim et al., 1999) and ovarian follicles (Chun et al., 1995). Exactly how cGMP protects against apoptosis is at present unclear. In serum-deprived PC12 cells, it is thought to involve the activation of protein kinase $G$ and the inhibition of caspase activation through the prevention of cytochrome c release (Kim et al., 1999). Recently, cGMP was found to suppress TNF $\alpha$ and ActD-induced apoptosis in hepatocytes (Li et al., 2000). In this study, there was a marked increase in activation of the serine/threonine kinase Akt, indicating a link between cGMP signalling and the Akt pathway. Activation of Akt can promote cell survival through phosphorylation of the pro-apoptotic protein Bad (Datta et al., 1997) and procaspase-9 (Cardone et al., 1998) and by preventing cytochrome c release from mitochondria (Kennedy et al., 1999). However, inhibition of Akt activation did not block the protective effect of cGMP in this study suggesting the activation of other survival pathways by cGMP.

\section{2. cGMP-independent mechanisms}

cGMP-independent mechanisms of NO protection of cell death include inhibition of lipid peroxidation (Rubbo et al., 1994) or peroxyl radical scavenging (Kotamraju et al., 2001), prevention of Bcl-2 cleavage (Kim et al., 1998a) and cytochrome c release and the induction of protective proteins such as $\mathrm{Hsp70}$ and $\mathrm{Bcl}-2$ (Kim and Suschek). In addition, many of the protective actions of $\mathrm{NO}$ are mediated by S-nitrosylation of proteins. S-nitrosylation involves the transfer of a nitric group to cysteine sulfhydryls, leading to the formation of a nitrosothiol (RSNO). While the movement and activity of nitric oxide is often restricting due to its very short half-life, nitrosothiols in comparison can be very stable compounds.

The caspases are a family of cysteine proteases that play a crucial role in apoptosis. Activation of caspase-3, one of the key executioners of apoptosis, results in cleavage of ICAD (inhibitor of caspaseactivated DNAse) and translocation of CAD (caspase-activated DNAse) to the nucleus ultimately resulting in DNA fragmentation. Caspase-3 activation is often considered as the point of no return in apoptosis and, thus, inhibition of caspases might provide a mechanism to abort the apoptotic cascade. Caspases contain a highly conserved cysteine residue within their active site and therefore are a target for S-nitrosylation. Caspases are also susceptible to oxidative modification by reactive oxygen species such as $\mathrm{H}_{2} \mathrm{O}_{2}$ and can be readily converted to disulfides and mixed disulfides under conditions of oxidative stress (Fadeel and Shacter). Evidence in support of caspase inhibition via Snitrosylation initially came from a study carried out on purified caspases. This study demonstrated reversible inhibition of seven members of the caspase family. Dithiothreitol (DTT), an agent that removes the NO group bound to the thiol group on proteins, reversed inhibition by NO, thereby indicating direct S-nitrosylation of the caspase catalytic cysteine residue by NO (Li et al., 1997a). NO 
inhibition of caspase activity has also been observed in a number of cells where NO donors were employed to inhibit caspase activities (Kim and Mohr). Endogenous NO has also been shown to inhibit caspase-3 like activity. In a study by Mannick et al. (1999), caspase-3 was found to be nitrosylated intracellularly and denitrosylated on Fas/Fas ligand cross-linking. Recently pro-caspase-3 was found to be S-nitrosylated on its catalytic-site cysteine in vivo (Rossig et al., 1999). Finally, NO has been reported to protect against Fas-induced liver injury by inhibiting caspase activity (Fiorucci et al., 2001). This caspase inhibition is DTT reversible, suggesting that cysteine S-nitrosylation is the underlying mechanism of caspase regulation by NO in this study.

In addition to S-nitrosylation of caspase-3, both caspase-1 and caspase-8 have also been reported to be nitrosylated in cells. NO produced by the NO donor SNAP or iNOS is sufficient to prevent TNFinduced apoptosis in hepatocytes. Both caspase- 8 and caspase- 3 were found to be reversibly inhibited and caspase- 8 was found to be S-nitrosylated in this system (Kim et al., 2000). Caspase-1, shown to be involved in both apoptosis and cytokine maturation, is also thought to be S-nitrosylated with the demonstration of the reversal of NO-induced inhibition of caspase-1 by DTT in macrophages (Kim et al., 1998b).

It is evident that NO is a potent inhibitor of caspase activity both in vitro and in vivo and that this inhibition is largely due to S-nitrosylation of the catalytic site cysteine conserved in all caspases. This discovery has significant implications for the regulation of apoptosis by NO. Under an oxidising intracellular environment, the caspases are inactivated, and therefore the cell must maintain a reducing environment in order for the execution phase of apoptosis to occur.

Evidence is accumulating that NO modulates the biological functions of many other intracellular signalling proteins by S-nitrosylation. These include tissue transglutaminase (Ttg), (Melino et al., 1997), the two cysteine-transcription factors NF kappa B (DelaTorre and DelaTorre), and AP-1 (Tabuchi et al., 1994), both implicated in the regulation of apoptosis, several ion channels (Broillet; Eu and Hart) and the protease calpain (Michetti et al., 1995) (Fig. 3). In addition, NO has also been reported to impair p53 function possibly through amino acid modifications such as S-nitrosylation (Chazotte-Aubert et al., 2001).

Redox modulation has been recognised as an important mechanism of regulation for the NMDA receptor. Excessive stimulation of the NMDA receptor-coupled ion channel and the subsequent generation of free radical species is implicated as a mechanism for neurotoxicity in many neurological diseases including Huntington's disease, Alzheimer's disease, stroke and AIDS dementia. The cell death pathway that ensues can either be necrotic or apoptotic depending on the intensity of the initial insult (Bonfoco et al., 1995). S-nitrosylation of the receptor inhibits excessive activity and as a result is neuroprotective (Lipton et al., 1998). Recently, site-directed mutagenesis identified a critical cysteine residue that was shown to react under physiological conditions with NO by Snitrosylation (Choi et al., 2000).

The anti-apoptotic activity of NO is now well established. Inhibition of caspases via S-nitrosylation is probably the best-characterised mechanism of inhibition and explains the extensive protective effect of NO. However, additional targets for S-nitrosylation containing critical cysteine residues are increasingly being identified. The transfer of the NO group to a free $\mathrm{SH}$ group is now gaining acceptance as a ubiquitous mode of regulation of protein function comparable to phosphorylation during apoptotic cell death. 


\subsection{NO and the mitochondrion}

Exposure of cells to NO concentrations of greater than $1 \mu \mathrm{m}$ can result in inhibition of apoptosis. However, while apoptosis is inhibited, necrotic cell death ensues. This may be due to a drop in cellular levels of ATP due to the failure of mitochondrial energy production and the greater dependence on ATP by apoptosis compared to necrosis (Leist and Leist). NO disrupts mitochondrial function by reversibly inactivating cytochrome coxidase, the terminal electron acceptor in the respiratory chain thus stimulating superoxide generation by the respiratory chain, production of peroxynitrite and ATP depletion (Cleeter and Cassina). Complex I and complex II are also inactivated by NO. It is thought that NO-induced complex I inhibition may result from S-nitrosylation of critical thiols (Clementi et al., 1998) while complex II is inactivated in vivo by mechanisms resembling ONOO--induced oxidative stress (Cassina and Radi, 1996).

Another site of action of NO on the mitochondria is the permeability transition pore (PTP) (Balakirev and Borutaite). There is now increasing evidence in support of redox regulation of cytochrome $c$ release during apoptosis (Kirkland and Franklin, 2001). The PTP plays an essential role in apoptosis; once opened, cytochrome $\mathrm{c}$ is released, resulting in the formation of the apoptososme, activation of caspase- 9 and execution of apoptosis. Recently, inhibition of mitochondrial PTP opening was identified as a novel site of action for NO signalling in apoptosis (Brookes et al., 2000). Inhibition of PTP opening would result in less cytochrome $c$ available to initiate apoptosis. This study suggests that a fine balance exists between the pro- and anti-apoptotic properties of $\mathrm{NO}$ at the level of the mitochondrion.

\section{Antioxidant defence mechanisms}

Both ROS and RNI can be generated as a result of normal metabolic processes or from toxic insult. It is clear that they are key participants in injury caused to cells, being capable of oxidative damage to all of the major classes of macromolecules, including proteins, lipids, carbohydrates and nucleic acids. Under normal conditions, antioxidant systems minimize the adverse effects caused by ROS (Fig. 1). However, when ROS overwhelm the biological defences of the cell, the result is oxidative stress. The importance of the antioxidant defence system is emphasised by antioxidant enzyme dysfunctions, which have been demonstrated to be associated with several neurodegenerative disorders including Parkinson's disease, Alzheimer's disease, Huntington's disease and amyotrophic lateral sclerosis (Sun and Mates).

\subsection{Primary defence mechanisms}

Antioxidants can be divided into primary or secondary defence mechanisms. Components of the primary antioxidant defence function to prevent oxidative damage directly by intercepting ROS before they can damage intracellular targets. It consists of superoxide dismutase (SOD), glutathione peroxidase (Gpx), catalase and thirodoxin reductase. Four classes of SOD have been identified to date. These are Mn-SOD, Cu,Zn-SOD, Ni-SOD and extracellular SOD. All four SOD enzymes destroy the free radical superoxide by converting it to $\mathrm{H}_{2} \mathrm{O}_{2}$ as follows: 
$\mathrm{H}_{2} \mathrm{O}_{2}$ is one of the major ROS in the cell. While low levels result in apoptosis, high levels can lead to necrosis or caspase-independent apoptosis (Hampton and Creagh). The primary defence mechanisms against $\mathrm{H}_{2} \mathrm{O}_{2}$ are catalase (Michiels et al., 1994) and GPx through the glutathione (GSH) redox cycle (Reed, 1990). Catalase is one of the most efficient enzymes known and cannot be saturated by $\mathrm{H}_{2} \mathrm{O}_{2}$ at any concentration (Lledias et al., 1998). It is present only in the peroxisome fraction whereas the GSH redox cycle exists in the cytosol and mitochondria. Catalase reacts with $\mathrm{H}_{2} \mathrm{O}_{2}$ to form water and molecular oxygen:

Overexpression of catalase in cytosolic or mitochondrial compartments has been demonstrated to protect cells against oxidative injury (Bai et al., 1999). In addition, catalase-overexpressing thymocytes are resistant to apoptosis (Tome et al., 2001). These studies not only demonstrate the cytotoxic effects of $\mathrm{H}_{2} \mathrm{O}_{2}$ but also emphasise the importance of catalase in antioxidant defence.

\subsection{Glutathione and the GSH redox cycle}

The GSH system is probably the most important cellular defence mechanism that exists in the cell. The tripeptide GSH ( $\gamma$-Glu-Cys-Gly), not only acts as an ROS scavenger but also functions in the regulation of the intracellular redox state. The system consists of $\mathrm{GSH}$, glutathione peroxidase and glutathione reductase. Glutathione peroxidase catalyses the reduction of $\mathrm{H}_{2} \mathrm{O}_{2}$ and other peroxidases and converts GSH to its oxidised disulfide form (GSSG) as outlined below.

GSSG is then reduced back to GSH by glutathione reductase. The ability of the cell to regenerate GSH (either by reduction of GSSG or new synthesis of GSH) is an important factor in the efficiency of that cell in managing oxidative stress. The rate-limiting step for GSH synthesis is catalysed by the enzyme $-\gamma$-glutamyl-cysteine synthase. Inducers of this enzyme have been reported to prevent glutamate toxicity (Murphy et al., 1991). In addition, - $\gamma$-glutamyl-cysteine synthase knockout mice embryos fail to gastrolate and develop distal apoptosis (Shi et al., 2000).

Under normal conditions, more than $95 \%$ of the GSH in a cell is reduced and so the intracellular environment is usually highly reducing. A depletion of intracellular GSH has been reported to occur with the onset of apoptosis in a number of studies (Oda and $\mathrm{Xu}$ ) and quite often is accompanied by a concomitant increase in ROS (Carmody et al., 1999). However, depletion of GSH will lower the reducing capacity of the cell and can therefore induce oxidative stress without the intervention of ROS. Depletion of GSH levels has been shown to be sufficient to induce apoptosis in a number of cell types and can also render cells more susceptible to apoptosis induced by subsequent stimuli (Fernandes and Wullner). The drop in GSH levels was found to be due to an increased rate of GSH efflux rather than an inhibition of synthesis or intracellular oxidation of the tripeptide. This has been reported in a study carried out in Fas-induced apoptosis in Jurkat T lymphocytes (van den Dobbelsteen et al., 1996). In this study, inhibitors of the GSH transporter prevented the efflux of $\mathrm{GSH}$, suggesting that the selective opening of a GSH-specific membrane channel is responsible. This is further supported by a more recent study where two specific inhibitors of carrier-mediated GSH extrusion were employed to decrease GSH efflux and apoptosis (Ghibelli et al., 1998).

\subsection{Bcl-2 as an antioxidant}

The proto-oncogene $\mathrm{Bcl}-2$ was initially characterised for its unique ability to block cell death triggered by a diverse array of agents. At least $15 \mathrm{Bcl}-2$ family members have now been identified, all 
possessing at least one of four conserved motifs known as Bcl-2 homology domains. The Bcl-2 family consists of both pro-apoptotic members such as Bax, Bad, Bid and Bik and anti-apoptotic members including $\mathrm{Bcl}-2, \mathrm{Bcl}-\mathrm{xL}, \mathrm{Bcl}-\mathrm{w}$ and $\mathrm{Mcl}-1$.

The mechanism by which $\mathrm{Bcl}-2$ protects against apoptosis remains somewhat elusive with many novel functions for Bcl-2 suggested (Bornkamm and Marin). The majority of research on $\mathrm{Bcl}-2$ and inhibition of apoptosis focuses on its interaction with and regulation of mitochondrial function particularly the mitochondrial permeability pore (Kluck; Yang; Susin and Susin). However, the localisation of $\mathrm{Bcl}-2$ to intracellular sites of oxygen free radical generation, including the cytoplasmic face of the mitochondrial outer membrane, endoplasmic reticulum and nuclear membranes led Hockenbery et al. (1993) to study possible antioxidant properties of $\mathrm{Bcl}-2$. This study demonstrated that $\mathrm{Bcl}-2$ expression protects cells against oxidant stress and led to the suggestion that $\mathrm{Bcl}-2$ is a death repressor molecule functioning in an antioxidant pathway. Further evidence in support of this suggestion came from the observation that $\mathrm{Bcl}-2$ knockout mice expressed a phenotype consistent with that of mice exposed to chronic oxidative stress (polycistic kidney disease and follicular hypopigmentation) (Veis et al., 1993). These early studies lead to research into possible redox aspects of $\mathrm{Bcl}-2$.

A study carried out in two mouse lymphoma cell lines demonstrated that overexpression of Bcl-2 leads to an increase in intracellular GSH levels (Mirkovic et al., 1997). Conversely, down-regulation of $\mathrm{Bcl}-2$ expression is associated with depletion of cellular glutathione (McCullough et al., 2001). These studies indicate that $\mathrm{Bcl}-2$ may modulate apoptosis through an intermediary pathway such as GSH metabolism. Further studies on the relationship between $\mathrm{Bcl}-2$ and GSH demonstrated that $\mathrm{Bcl}-2$ expression alters GSH compartmentalisation (Voehringer et al., 1998). Overexpression of Bcl-2 leads to a relocalisation of GSH from the cytosol to the nucleus. It is possible then that Bcl-2 inhibits apoptosis through modulation of intracellular glutathione levels and its redistribution to the nucleus. Such alterations can, in turn, change nuclear redox potential, creating a highly reducing environment within the cell. The transcription factors $\mathrm{p} 53, \mathrm{AP}-1$ and NF-KB are sensitive to redox change primarily as they bind DNA in a redox sensitive mechanism (Morel and Barouki, 1999). The changes in nuclear redox potential might then alter DNA binding of these transcription factors. The transcriptional changes observed by Voehringer et al. (2000) using DNA microarrays and cells with different levels of $\mathrm{Bcl}-2$ are thought to be caused by $\mathrm{Bcl}-2$ mediated nuclear GSH changes. It is hypothesised, therefore, that GSH acts via a Bcl-2-dependent mechanism as a transcriptional regulator by altering the nuclear redox environment.

Clearly, there is considerable evidence in support of the hypothesis that $\mathrm{Bcl}-2$ inhibits apoptosis through an antioxidant effect. However, there is also evidence to suggest that $\mathrm{Bcl}-2$ acts against nonoxidative injury. This is supported by the ability of $\mathrm{Bcl}-2$ to protect against apoptosis in systems where ROS generation is considered to be negligible (Jacobson and Shimizu). These studies were carried out in near-anaerobic conditions on the assumption that cells do not generate significant levels of ROS under such conditions. Measurement of ROS were not carried out in these studies and since then, Degli Esposti and McLennan (1998) have demonstrated that mitochondria and cells do produce ROS in virtual anaerobics. Therefore, the apparent contradiction in the mechanism of $\mathrm{Bcl}-2$ protection against apoptosis may be due, at least in part, to lack of crucial measurements of ROS. These studies emphasise the importance of employing adequate detection methods when studying ROS generation. 


\section{Measuring ROS/RNI}

ROS and RNI are short-lived species and usually have half-lives of less than a second. Bursts of ROS and RNI generation in cell signalling are generally over after a few seconds or a few minutes. As a result, detecting oxidative stress in apoptosis can be difficult without the right approach.

\subsection{Antioxidants and scavengers}

Antioxidants are powerful tools with which to demonstrate the involvement of ROS in apoptosis. As we described earlier, the cell possesses numerous antioxidants to buffer the generation of potentially damaging oxidising agents.

There are many artificial antioxidants that can mimic the effects of natural antioxidants in a cell. Zinc chloride, $\mathrm{N}$-acetyl-1-cysteine, 1,10-phenanthroline and pyrrolidine dithiocarbomate are wellestablished antioxidants. ROS-dependent apoptosis can be inhibited with these compounds (Carmody; Friesen and Kirkland). Gorman et al. (1999) demonstrated that ROS production induces hsp72 and hsp27 expression in HL60 cells during stress responses. Preincubation with the antioxidants pyrrolidine dithiocarbomate and 1,10 phenanthroline actually augmented apoptosis. The authors concluded that increases in ROS contributed to the increased expression of hsp72 and hsp27 and protected against apoptosis (Gorman et al., 1999).

While ROS may be generated by many different enzymatic and nonenzymatic mechanisms in a cell, $\mathrm{RNI}$ are almost always generated by NOS. Antioxidants are usually less effective in determining the involvement of NO in apoptosis. This is emphasised by DTT, which has been employed to reverse Snitrosylation of caspases (Li et al., 1997a) but can also reverse peroxide-induced caspase inactivation (Carmody and Cotter, 2000). It is important, therefore, to verify S-nitrosylation of proteins and hence the involvement of $\mathrm{NO}$ in apoptosis using analytical methods such as mass spectrometry (Zech et al., 1999). Scavengers such as PTIO can also be used to determine the involvement of NO in cell death ( Boullerne et al., 1999). However, general NOS inhibitors are usually far more effective.

While antioxidants and NO scavengers are useful tools in determining the involvement of ROS/RNI in apoptosis, one must also consider the limitations of these chemicals. Primarily, changing the redox state of a cell may profoundly affect cellular signaling pathways. Also, because many antioxidants are analogues of biological substrates, they may directly interfere with cellular signaling pathways. Often, one antioxidant may only partially affect apoptosis while another may alter the process completely. It is prudent to use at least two structurally unrelated antioxidants when determining the role of ROS in apoptosis.

\subsection{ROS detection}

There are many methods for measuring free radical production in cells. Chemiluminescence of luminol (Suzuki; Dahlgren and Mellqvist) and lucigenin (Gyllenhammar, 1987), cytochrome c reduction (Dahlgren and Karlsson, 1999), ferrous oxidation of xylenol orange (Nourooz-Zadeh, 1999) and DCFH-DA (Carmody; Tammariello and Ottonello) have all been used successfully to detect ROS generation. The most straightforward techniques use cell permeable fluorescent and chemiluminescent probes. Flow cytometry or fluorimetry can be used for the detection of ROS with fluorescent probes. 
2'-7'-Dichlorodihydrofluorescein diacetate (DCFH-DA) is one of the most widely used techniques for directly measuring the redox state of a cell. This is a cell permeable, relatively nonfluorescent molecule. It has many advantages over other techniques developed. It is very easy to use, extremely sensitive to changes in the redox state of a cell, inexpensive and can be used to follow changes in ROS over time. Activity of cellular esterases cleave DCFH-DA into 2'-7'-dichlorodihydrofluorescein (DCFH2). Peroxidases, cytochrome $\mathrm{c}$ and Fe2+ can all oxidise DCFH2 to 2'-7'-dichlorofluorescein (DCF) in the presence of hydrogen peroxide (Fig. 4A). Accumulation of DCF in cells may be measured by an increase in fluorescence at $530 \mathrm{~nm}$ when the sample is excited at $485 \mathrm{~nm}$. Fluorescence at $530 \mathrm{~nm}$ can be measured using a flow cytometer and is assumed to be proportional to the concentration of hydrogen peroxide in the cells (Bass and Royall) (Fig. 4B).

It is important to understand the limitations of using this probe. Although DCFH-DA is used to measure the concentration of hydrogen peroxide in cells, superoxide and NO generation are also capable of oxidising DCFH2 (Rao et al., 1992). The presence of SOD in the cytosol (Cu,Zn-SOD), mitochondria (Mn-SOD) and extracellular space (Ec-SOD) all convert superoxide into hydrogen peroxide, resulting in the accumulation of DCF in the cells. Inhibitors of SOD can be used to eliminate this source of hydrogen peroxide production. DCFH2 may also be oxidised independently of hydrogen peroxide. Nitric oxide reacts with superoxide producing peroxynitrite. DCFH2 can be directly oxidised to DCF by peroxynitrite (Fig. 4a). Inhibitors of NOS should be used to prevent NO mediated DCFH2 oxidation (Kooy et al., 1997).

DCF, the oxidised fluorescent product of DCFH2, is membrane permeable and can leak out of cells over time. Detecting slow hydrogen peroxide production over time can be difficult (Ubezio and Civoli, 1994). Various analogues have been developed that retain their fluorescent properties but are charged at physiological $\mathrm{pH}$, which allows them to accumulate in the cell even during slow hydrogen peroxide production.

Some cell types have low esterase activity. This can have important implications for detecting ROS because DCFH-DA needs to be hydrolysed to DCFH2 by cellular esterases. DCFH-DA cannot be oxidised by hydrogen peroxide to give a fluorescent product. Brubacher and Bols (2001) have shown that DCFH-DA underestimates ROS generation in rainbow trout macrophages. In contrast, both $\mathrm{DCFH} 2$ and the cytochrome $\mathrm{c}$ reduction assay measure comparable amounts of ROS production. The authors conclude that careful consideration must be given to the levels of esterase activity in cells before using this probe. In cells with low esterase activity or where the esterases are sequestered in inaccessible parts of the cell, using the deacetylated probe DCFH2 or some other assay is advised.

In a model system using xanthine oxidase to generate superoxide, DCFH2 was found to be insensitive to a 17 -fold change in superoxide production. In contrast, nanomolar concentrations of cytochrome c caused an accumulation of the fluorescent DCF (Burkitt and Wardman, 2001). The authors conclude that in apoptotic cells, accumulation of DCF is due to cytochrome c release and not superoxide. This is an important observation but DCFH2 is believed to measure hydrogen peroxide directly and not superoxide. It is not surprising that here fluorescence is not observed over a 17-fold change in concentration of superoxide. Certainly, there is clear evidence that DCFH-DA is able to assess accurately the redox state in most cell systems. However, care should be taken to validate the experiments using other techniques such as antioxidants and inhibitors. Used carefully, this probe can be a powerful tool for analysing ROS production in cells. 
Luminol-dependent chemiluminescence (luminol-dependent CL) (Allen and Loose, 1976) and lucigenin-dependent chemiluminescence (lucigenin-dependent CL) (Minkenberg and Ferber, 1984) are alternative, cell permeable methods for detecting ROS production. Luminol is not sensitive to superoxide production (Faulkner and Fridovich, 1993) but may undergo a chemiluminescent oxidation with hydrogen peroxide (Littauer and Caraceni) and peroxynitrite (Kooy et al., 1997). Lucigenin is specific for superoxide production, and only luminesces weakly in the presence of hydrogen peroxide (Gyllenhammar and Faulkner).

Recently, a variation of the luminol-dependent $\mathrm{CL}$ assay has been developed. The assay is based on the oxidation of luminol by sodium hypochlorite $(\mathrm{NaOCl})$. Hydrogen peroxide reacts with this oxidised product, generating an excited molecule capable of luminescence. This assay is specific for hydrogen peroxide, unlike luminol-dependent $\mathrm{CL}$ and can detect nanomolar concentrations of hydrogen peroxide (Mueller and Mueller).

Luminol- and lucigenin-dependent $\mathrm{CL}$ possess many of the advantages of fluorescent probes such as DCFH-DA. They are easy to use, sensitive, inexpensive and can measure ROS generation in intact cells over time. They possess advantages over DCFH-DA in that they do not need to be cleaved by esterases and can be used in systems with low esterase activity. Also, cytochrome $c$ is not able to catalyse chemiluminescent reactions and cannot interfere with ROS measurements during apoptosis.

Controversy has surrounded lucigenin since it was suggested that redox cycling of lucigenin can lead to extra superoxide production (Liochev and Liochev). Barbacanne et al. (2000) suggest that electron donors such as NADH and NADPH yield large amounts of superoxide when incubated with lucigenin. The authors found that in systems where very low levels of superoxide are produced, lucigenin must be used at a concentration that causes extra superoxide generation. When measuring low levels of superoxide, alternative methods of detection including DCFH-DA or cytochrome c reduction should be used instead. Further studies, however, validate lucigenin-dependent $C L$ as an assay for superoxide production in most systems. Li et al. (1998) have shown that lucigenin produces superoxide when used above a threshold concentration in vitro. The authors analysed superoxide production in numerous enzymatic and cellular systems including mitochondrial and NADPH oxidase generated superoxide. They demonstrated that lucigenin effectively detects low levels of superoxide without causing additional superoxide production.

\subsection{Nitric oxide detection}

Like ROS detection, there exist a wide variety of techniques for detecting RNI in biological samples including -3H-arginine metabolism (Bulotta et al., 2001), chemiluminescence of NO reacting with ozone (Misso et al., 2000), anion exchange HPLC (Marzinzig et al., 1997), fluorescent probes such as 4,5-di aminofluorescein (DAF2-DA) (Nakatsubo and Nakatsubo) and DCFH-DA (Kooy et al., 1997), spin traps such as $\mathrm{N}$-(dithiocarbanoyl)-N-methyl- -glucamine (MGD) (Venkataraman et al., 2000) and the Griess reagent (Green and Archer). With the exception of DAF2-DA and MGD, all of the assays above detect NO degradation products such as nitrites, nitrates and peroxynitrites.

When measuring the end products of NO metabolism, the Griess reaction is usually the preferred assay. It is the most sensitive and has the largest linear range for routine analysis of nitric oxide (Marzinzig et al., 1997). In the Griess reaction, nitrite reacts with sulfanalic acid and N-(1-naphthly)- 
ethylenediamine dihydrochloride in the presence of phosphoric acid and produces a coloured azo dye, which can be measured colorimetrically at $548 \mathrm{~nm}$. This value is proportional to the amount of nitrite in the solution. The detection limit of the Griess reagent is between $100 \mathrm{nM}$ and $1 \mu \mathrm{M}$ (Tracey et al., 1990).

An adaptation of this protocol by Schulz et al. (1999) is 500 times more sensitive than the traditional Griess reaction and 7 times more sensitive than anion exchange HPLC. It can be used when great sensitivity of detection is required, but is not necessary in the majority of cases of apoptosis.

One major drawback to the Griess reaction is that it is unable to detect changes in NO production in cells over time. When measuring real time changes in NO production in cells, an alternative assay such as DAF-2 DA is required. DAF-2 DA is cell permeable and reacts with the NO free radical, producing a highly fluorescent derivative. DAF-2 DA is excited at $492 \mathrm{~nm}$ and fluoresces at $515 \mathrm{~nm}$. Like DCFH-DA, esterase activity is required before the probe can be oxidised and fluoresces. $A$ negative control for DAF-2 DA is also available. It is called 4-aminofluorescein diacetate (4AF DA) (Kojima et al., 1998).

DAF-2 DA fluorescence has been measured in a fluorimeter and also using confocal microscopy. However, Broillet and colleagues have shown that the intense light produced in laser scan confocal microscopes is capable of enhancing DAF-2 DA fluorescence in the presence of NO. Also, Ca2+ greatly enhances DAF-2 DA fluorescence in the presence of NO. Also Ca2+ greatly enhances DAF-2 DA fluorescence in the presence of NO. DAF-2 DA will fluoresce in organelles with high Ca2+ concentration including the mitochondria and endoplasmic reticulum even though these may not be the original sources of NO production. Also, using DAF-2 DA in systems where intracellular Ca2+ increases may also produce misleading results of NO production. Because of these factors, confocal microscopy measurements of DAF-2 DA fluorescence in cells is prone to numerous errors (Broillet et al., 2001). Changes in intracellular Ca2+ occurs in several apoptotic systems (Lopez; Creagh and Donovan). When measuring NO in such systems, it is necessary to confirm NO production using another assay such as the Griess reaction (Rodriguez-Lopez et al., 2000) or specific NOS inhibitors (Donovan et al., 2001).

\subsection{Glutathione}

The redox state of a cell can be altered without an increase in ROS or RNI generation. As discussed earlier, this can occur due to a depletion of glutathione, the most important antioxidant defence mechanism in the cell. Measuring glutathione levels in a cell, therefore, can often be valuable in determining the overall redox state of the cell. Ortho-pthaldialdehyde (OPT) (Domenicotti et al., 2000), 5,5-dithiobis(2-nitrobenzoic acid) (Li et al., 1997b) and monochlorobimane (Rice et al., 1986) have all proved useful in determining the intracellular concentrations of glutathione.

Monochlorobimanes and bromobimanes are versatile, membrane permeable nonfluorescent probes that bind irreversibly to sulfydryl groups yielding a fluorescent product (Kosower and Kosower, 1995). Fluorescence can be measured in a fluorimeter with excitation and emission maxima set at 395 and $480 \mathrm{~nm}$, respectively, or using flow cytometry (Rice et al., 1986). The authors reported very low reactivity of monochlorobimane with protein sulfydryl residues other than GSH. However, it is advisable to determine the glutathione levels using a protein-free assay. OPT, another fluorescent probe, can accurately assess total glutathione levels in protein precipitated cell lysates (Kaul et al., 
1998). It is also possible to estimate the ratio of GSH/GSSG from experiments using monochlorobimanes and OPT.

Depletion of intracellular glutathione levels can be achieved either using inhibitors of glutathione synthesis or by metabolising intracellular glutathione. -buthionine-S,R-sulfoximine (BSO) is a cell permeable, selective and irreversible inhibitor of the enzyme $\gamma$ glutamyl-cysteine synthetase, the first step in synthesising glutathione (Terradez et al., 1993). Glutathione-S-transferase (GST) substrates can also be used to deplete glutathione levels in cells. Diethylmaleate, a GST substrate, is conjugated to GSH by glutathione-S-transferase and subsequently eliminated from the cell (Saez et al., 1985). A recent study that employed diethylmaleate successfully resulted in GSH depletion and induced apoptosis in rat hepatocytes (Domenicotti et al., 2000).

\subsection{Inhibitors of NOS}

NO is synthesised by three major NOS isoforms; iNOS, eNOS and nNOS (Nathan, 1997). Inhibitors of NOS activity are often effective in demonstrating the involvement of nitric oxide in apoptosis. General inhibitors have a similar potency against the three NOS isoforms. Examples of general inhibitors include NG-nitro-L-arginine methyl ester (L-NAME) (Rees et al., 1990) and NG-methyl-Larginine (L-NMMA) (Joly and Olken). Specific inhibitors display greater affinity for one or two NOS isoforms. Examples of these include 7-nitroindazole (7-NI) (Bland and Moore), N5-(1-iminoethyl)-Lornithine (L-NIO) (Rees et al., 1990) and N5-(1-iminoethyl)-L-lysine (L-NIL) (Moore et al., 1994). The majority of NOS inhibitors are derived from amino acids and usually do not affect other metabolic pathways at the concentrations needed for NOS inhibition.

General NOS inhibitors can be used to determine whether the production of NO is directly involved in apoptosis. Specific inhibitors of NOS can be used to characterise further the source of NO generation. 7-NI and 3-bromo-7-NI are potent inhibitors of nNOS (Bland-Ward and Moore, 1995) and have been effectively used to inhibit apoptosis (Williams et al., 1998).

Specific inhibitors of iNOS are also available. -NIL exhibits a 30-fold selectivity for iNOS over nNOS (Moore et al., 1994). However, perhaps the most potent and specific inhibitor of iNOS is N-(3(aminomethyl)benzyl) acetomidine (1400W). 1400W irreversibly inhibits iNOS with a 5000 -fold greater selectivity than eNOS and 200 -fold greater selectivity over iNOS. Although $1400 \mathrm{~W}$ can be toxic to cells, inhibition of iNOS usually occurs far below its threshold for cytotoxicity (Garvey et al., 1997).

There have not been any specific eNOS inhibitors developed. However, a combination of general inhibitors against NOS and specific inhibitors for nNOS and iNOS can elucidate the role of eNOS in oxidative stress and apoptosis.

\subsection{Inhibitors of ROI}

Although antioxidants are more effective in determining the role of $\mathrm{ROI}$ in apoptosis, there are also inhibitors of ROI production available. These can be very useful in determining the source of ROI generation in oxidative stress, but care should be exercised when using them. Some inhibitors of ROI production are nonspecific and/or toxic to the cells or tissues in which they are used. 
As we mentioned earlier, mitochondria are the primary source of ROI production in apoptosis. Two sites on the ETC, NADH-ubiquinone oxidoreductase (complex I) and ubiquinol-cytochrome $\mathrm{c}$ oxidoreductase (complex III) are capable of generating superoxide. Rotenone is an inhibitor of electron transport in the ETC, binding to a site on complex I. It has been used as a specific inhibitor of superoxide production by complex I. Myxothiazol inhibits electron transport at complex III and has been used as a specific inhibitor of superoxide generation at complex III (Li et al., 1998) (Fig. 2).

Another important source of ROI in apoptosis is NADPH oxidase. NADPH oxidase activity can be inhibited using diphenylene iodonium (DPI) (O and Tammariello). A drawback to using DPI is that it also inhibits NOS activity (Stuehr et al., 1991).

Inhibition of SOD and catalase is sometimes desirable. SOD inhibitors include diethyldithiocarbamate (DDC) (Liu and Jan, 2000) and triethylenetetramine (An and Hsie, 1993). Cyanide, a nonspecific inhibitor, can also inhibit SOD activity. These only inhibit Cu,Zn-SOD and have no effect on Mn-SOD activity (Iqbal and Whitney, 1991). Catalase may be inhibited using the specific aminotriazole or the nonspecific inhibitor cyanide (Putnam et al., 2000). Finally, inhibition of cytochrome P450 enzyme activity, a major source of ROI in chemically induced oxidative stress, is possible using SFK or 1aminobenzotriazole (Shiba and Shimamoto, 1999).

\section{Acknowledgements}

Fighting Blindness Ireland, Irish Cancer Society, Health Research Board Ireland and Enterprise Ireland are acknowledged.

\section{References}

Allen and Loose, 1976. R.C. Allen and L.D. Loose, Phagocytic activation of a luminol-dependent chemiluminescence in rabbit alveolar and peritoneal macrophages. Biochem. Biophys. Res. Commun. 69 (1976), p. 245.

Almeida and Bolanos, 2001. A. Almeida and J.P. Bolanos, A transient inhibition of mitochondrial ATP synthesis by nitric oxide synthase activation triggered apoptosis in primary cortical neurons. J. Neurochem. 77 (2001), p. 676.

An and Hsie, 1993. J. An and A.W. Hsie, Polymerase chain reaction-based deletion screening of bleomycin induced 6-thioguanine-resistant mutants in Chinese hamster ovary cells: the effects of an inhibitor and a mimic of superoxide dismutase. Mutat. Res. 289 (1993), p. 215.

Andreka et al., 2001. P. Andreka, J. Zang, C. Dougherty, T.I. Slepak, K.A. Webster and N.H. Bishopric, Cytoprotection by Jun kinase during nitric oxide-induced cardiac myocyte apoptosis. Circ. Res. 88 (2001), p. 305.

Archer, 1993. S. Archer, Measurement of nitric oxide in biological models. FASEB J. 7 (1993), p. 349.

Asahi et al., 1995. M. Asahi, J. Fujii, K. Suzuki, H.G. Seo, T. Kuzuya, M. Hori, M. Tada, S. Fujii and N. Taniguchi , Inactivation of glutathione peroxidase by nitric oxide: implication for cytotoxicity. J. Biol. Chem. 270 (1995), p. 21035. 
Bai et al., 1999. J. Bai, A.M. Rodriguez, J.A. Melendez and A.I. Cederbaum , Overexpression of catalase in cytosolic or mitochondrial compartment protects HepG2 cells against oxidative injury. J. Biol. Chem. 274 (1999), p. 26217.

Balakirev et al., 1997. M. Balakirev, V.V. Khramtsov and G. Zimmer, Modulation of the mitochondrial permeability transition by nitric oxide. Eur. J. Biochem. 246 (1997), p. 710.

Barbacanne et al., 2000. M.A. Barbacanne, J.P. Souchard, B. Darblade, J.P. Iliou, F. Nepveu, B. Pipy, F. Bayard and J.F. Arnal, Detection of superoxide anion released extracellularly by endothelial cells using cytochrome c reduction, ESR, fluorescence and lucigenin-enhanced chemiluminescence techniques. Free Radic. Biol. Med. 29 (2000), p. 388.

Bass et al., 1983. D.A. Bass, J.W. Parce, L.R. Dechatelet, P. Szejda, M.C. Seeds and M. Thomas, Flow cytometric studies of oxidative product formation by neutrophils: a graded response to membrane stimulation. J. Immunol. 130 (1983), p. 1910.

Bates et al., 1995. T.E. Bates, A. Loesch, G. Burnstock and J.B. Clark, Immunocytochemical evidence for a mitochondrially located nitric oxide synthase in brain and liver. Biochem. Biophys. Res. Commun. 213 (1995), p. 896.

Bates et al., 1996. T.E. Bates, A. Loesch, G. Burnstock and J.B. Clark, Mitochondrial nitric oxide synthase: a ubiquitous regulator of oxidative phosphorylation?. Biochem. Biophys. Res. Commun. 218 (1996), p. 40.

Beauvais et al., 1995. F. Beauvais, L. Michel and L. Dubertret, The nitric oxide donors, azide and hydroxylamine, inhibit the programmed cell death of cytokine-deprived human eosinophils. FEBS Lett. 361 (1995), p. 229.

Beyer, 1992. R.E. Beyer, An analysis of the role of coenzyme $Q$ in free radical generation and as an antioxidant. Biochem. Cell. Biol. 70 (1992), p. 390.

Binder et al., 1999. C. Binder, M. Schulz, W. Hiddemann and M. Oellerich, Induction of inducible nitric oxide synthase is an essential part of tumor necrosis factor-alpha-induced apoptosis in MCF-7 and other epithelial tumor cells. Lab. Invest. 79 (1999), p. 1703.

Bland-Ward and Moore, 1995. P.A. Bland-Ward and P.K. Moore , 7-Nitro indazole derivatives are potent inhibitors of brain, endothelium and inducible isoforms of nitric oxide synthase. Life Sci. 57 (1995), p. L131.

Bonfoco et al., 1995. E. Bonfoco, D. Krainc, M. Ankarcrona, P. Nicotera and S.A. Lipton, Apoptosis and necrosis: two distinct events induced, respectively, by mild and intense insults with $\mathrm{N}$-methyl- aspartate or nitric oxide/superoxide in cortical cell cultures. Proc. Natl. Acad. Sci. U. S. A. 92 (1995), p. 7162.

Bornkamm and Richter, 1995. G.W. Bornkamm and C. Richter , A link between the antioxidant defense system and calcium: a proposal for the biochemical function of Bcl-2. Curr. Top. Microbiol. Immunol. 194 (1995), p. 323. 
Borutaite et al., 2000. V. Borutaite, R. Morkuniene and G.C. Brown, Nitric oxide donors, nitrosothiols and mitochondrial respiration inhibitors induce caspase activation by different mechanisms. FEBS Lett. 467 (2000), p. 155.

Boullerne et al., 1999. A.I. Boullerne, L. Nedelkoska and J.A. Benjamins, Synergism of nitric acid and iron in killing the transformed murine oligodendrorcyte cell line N20.1. J. Neurochem. 73 (1999), p. 1050.

Bringold et al., 2000. U. Bringold, P. Ghafourifar and C. Richter, Peroxynitrite formed by mitochondrial NO synthase promotes mitochondrial Ca2+ release. Free Radic. Biol. Med. 29 (2000), p. 343.

Broillet, 2000. M.C. Broillet, A single intracellular cysteine residue is responsible for the activation of the olfactory cyclic nucleotide-gated channel by NO. J. Biol. Chem. 275 (2000), p. 15135.

Broillet et al., 2001. M. Broillet, O. Randin and J. Chatton, Photoactivation and calcium sensitivity of the fluorescent NO indicator 4,5-diaminofluorescein (DAF-2): implications for cellular NO imaging. FEBS Lett. 491 (2001), p. 227.

Brookes et al., 2000. P.S. Brookes, E.P. Salinas, K. Darley-Usmar, J.P. Eiserich, B.A. Freeman, V.M. Darley-Usmar and P.G. Anderson, Concentration-dependent effects of nitric oxide on mitochondrial permeability transition and cytochrome c release. J. Biol. Chem. 275 (2000), p. 20474.

Brubacher and Bols, 2001. J.L. Brubacher and N.C. Bols , Chemically de-acetylated 2',7'dichlorodihydrofluorescein diacetate as a probe of respiratory burst activity in mononuclear phagocytes. J. Immunol. Methods 251 (2001), p. 81.

Bulotta et al., 2001. S. Bulotta, R. Barsacchi, D. Rotiroti, N. Borgese and E. Clementi , Activation of the endothelial nitric-oxide synthase by tumor necrosis factor-alpha: a novel feedback mechanism regulating cell death. J. Biol. Chem. 276 (2001), p. 6529.

Burkitt and Wardman, 2001. M.J. Burkitt and P. Wardman, Cytochrome $\mathrm{c}$ is a potent catalyst of dichlorofluorescin oxidation: implications for the role of reactive oxygen species in apoptosis. Biochem. Biophys. Res. Commun. 282 (2001), p. 329.

Cadenas et al., 1983. E. Cadenas, H. Sies, W. Nastainczyk and V. Ullrich, Singlet oxygen formation detected by low-level chemiluminescence during enzymatic reduction of prostaglandin $\mathrm{G} 2$ to $\mathrm{H} 2$. Hoppe-Seyler Z. Physiol. Chem. 364 (1983), p. 519.

Caraceni et al., 1994. P. Caraceni, E.R. Rosenblum, D.H. Van Thiel and A.B. Borle, Reoxygenation injury in isolated rat hepatocytes: relation to oxygen free radicals and lipid peroxidation. Am. J. Physiol. 266 (1994), p. G799.

Cardone et al., 1998. M.H. Cardone, N. Roy, H.R. Stennicke, G.S. Salvesen, T.F. Franke, E. Stanbridge, S. Frisch and J.C. Reed, Regulation of cell death protease caspase-9 by phosphorylation. Science 282 (1998), p. 1318.

Carmody and Cotter, 2000. R.J. Carmody and T.G. Cotter , Oxidative stress induces caspaseindependent retinal apoptosis in vitro. Cell Death Differ. 7 (2000), p. 282. 
Carmody et al., 1999. R.J. Carmody, A.J. McGowan and T.G. Cotter, Reactive oxygen species as mediators of photoreceptor apoptosis in vitro. Exp. Cell Res. 248 (1999), p. 520.

Cassina and Radi, 1996. A. Cassina and R. Radi , Differential inhibitory action of nitric oxide and peroxynitrite on mitochondrial electron transport. Arch. Biochem. Biophys. 328 (1996), p. 309.

Chazotte-Aubert et al., 2001. L. Chazotte-Aubert, O. Pluquet, P. Hainaut and H. Ohshima, Nitric oxide prevents gamma-radiation-induced cell cycle arrest by impairing p53 function in MCF-7 cells. Biochem. Biophys. Res. Commun. 281 (2001), p. 766.

Choi et al., 2000. Y.B. Choi, L. Tenneti, D.A. Le, J. Ortiz, G. Bai, H.S. Chen and S.A. Lipton, Molecular basis of NMDA receptor-coupled ion channel modulation by S-nitrosylation. Nat. Neurosci. 3 (2000), p. 15.

Christen et al., 1997. S. Christen, A.A. Woodall, M.K. Shigenaga, P.T. Southwell-Keely, M.W. Duncan and B.N. Ames, Gamma-tocopherol traps mutagenic electrophiles such as $\mathrm{NO}(\mathrm{X})$ and complements alpha-tocopherol: physiological implications. Proc. Natl. Acad. Sci. U. S. A. 94 (1997), p. 3217.

Chun et al., 1995. S.Y. Chun, K.M. Eisenhauer, M. Kubo and A.J. Hsueh, Interleukin 1 beta suppresses apoptosis in rat ovarian follicles by increasing nitric oxide production. Endocrinology 136 (1995), p. 3120.

Cleeter et al., 1994. M.W. Cleeter, J.M. Cooper, V.M. Darley-Usmar, S. Moncada and A.H. Schapira, Reversible inhibition of cytochrome c oxidase, the terminal enzyme of the mitochondrial respiratory chain, by nitric oxide. Implications for neurodegenerative diseases. FEBS Lett. 345 (1994), p. 50.

Clementi et al., 1998. E. Clementi, G.C. Brown, M. Feelisch and S. Moncada, Persistent inhibition of cell respiration by nitric oxide: crucial role of S-nitrosylation of mitochondrial complex I and protective action of glutathione. Proc. Natl. Acad. Sci. U. S. A. 95 (1998), p. 7631.

Cohen, 1997. G.M. Cohen , Caspases: the executioners of apoptosis. Biochem. J. 326 (1997), p. 1.

Cooney et al., 1993. R.V. Cooney, A.A. Franke, P.J. Harwood, V. Hatch-Pigott, L.J. Custer and L.J. Mordan , Gamma-tocopherol detoxification of nitrogen dioxide: superiority to alpha-tocopherol. Proc. Natl. Acad. Sci. U. S. A. 90 (1993), p. 1771.

Creagh and Cotter, 1999. E.M. Creagh and T.G. Cotter, Selective protection by hsp 70 against cytotoxic drug-, but not Fas-induced T-cell apoptosis. Immunology 97 (1999), p. 36.

Creagh et al., 2000. E.M. Creagh, R.J. Carmody and T.G. Cotter, Heat shock protein 70 inhibits caspase-dependent and-independent apoptosis in Jurkat T cells. Exp. Cell Res. 257 (2000), p. 58.

Cui et al., 1994. S. Cui, J.S. Reichner, R.B. Mateo and J.E. Albina, Activated murine macrophages induce apoptosis in tumor cells through nitric oxide-dependent or -independent mechanisms. Cancer Res. 54 (1994), p. 2462.

D'Acquisto et al., 2001. F. D'Acquisto, F. de Cristofaro, M.C. Maiuri, G. Tajana and R. Carnuccio, Protective role of nuclear factor kappa B against nitric oxide-induced apoptosis in $\mathrm{J774}$ macrophages. Cell Death Differ. 8 (2001), p. 144. 
Dahlgren and Karlsson, 1999. C. Dahlgren and A. Karlsson, Respiratory burst in human neutrophils. J. Immunol. Methods 232 (1999), p. 3.

Datta et al., 1997. S.R. Datta, H. Dudek, X. Tao, S. Masters, H. Fu, Y. Gotoh and M.E. Greenberg , Akt phosphorylation of BAD couples survival signals to the cell-intrinsic death machinery. Cell 91 (1997), p. 231.

Degli Esposti and McLennan, 1998. M. Degli Esposti and H. McLennan, Mitochondria and cells produce reactive oxygen species in virtual anaerobiosis: relevance to ceramide-induced apoptosis. FEBS Lett. 430 (1998), p. 338.

DelaTorre et al., 1997. A. DelaTorre, R.A. Schroeder and P.C. Kuo , Alteration of NF-kappa B p50 DNA binding kinetics by S-nitrosylation. Biochem. Biophys. Res. Commun. 238 (1997), p. 703.

DelaTorre et al., 1999. A. DelaTorre, R.A. Schroeder, C. Punzalan and P.C. Kuo, Endotoxin-mediated S-nitrosylation of p50 alters NF-kappa B-dependent gene transcription in ANA-1 murine macrophages. J. Immunol. 162 (1999), p. 4101.

Dimmeler et al., 1999. S. Dimmeler, I. Fleming, B. Fisslthaler, C. Hermann, R. Busse and A.M. Zeiher, Activation of nitric oxide synthase in endothelial cells by Akt-dependent phosphorylation. Nature 399 (1999), p. 601.

Dobashi et al., 1997. K. Dobashi, K. Pahan, A. Chahal and I. Singh , Modulation of endogenous antioxidant enzymes by nitric oxide in rat C6 glial cells. J. Neurochem. 68 (1997), p. 1896.

Domenicotti et al., 2000. C. Domenicotti, D. Paola, A. Vitali, M. Nitti, C. d'Abramo, D. Cottalasso, G. Maloberti, F. Biasi, G. Poli, E. Chiarpotto, U.M. Marinari and M.A. Pronzato, Glutathione depletion induces apoptosis of rat hepatocytes through activation of protein kinase $\mathrm{C}$ novel isoforms and dependent increase in AP-1 nuclear binding. Free Radic. Biol. Med. 29 (2000), p. 1280.

Donald et al., 2001. S.P. Donald, X.Y. Sun, C.A. Hu, J. Yu, J.M. Mei, D. Valle and J.M. Phang, Proline oxidase, encoded by $\mathrm{p} 53$-induced gene- 6 , catalyzes the generation of proline-dependent reactive oxygen species. Cancer Res. 61 (2001), p. 1810.

Donovan et al., 2001. M. Donovan, R.J. Carmody and T.G. Cotter , Light-induced photoreceptor apoptosis in vivo requires nNOS and guanylate cyclase activity and is caspase-3 independent. J. Biol. Chem. 8 (2001), p. 8.

Dupraz et al., 2000. P. Dupraz, S. Cottet, F. Hamburger, W. Dolci, E. Felley-Bosco and B. Thorens, Dominant negative MyD88 proteins inhibit interleukin-1beta/interferon-gamma-mediated induction of nuclear factor kappa B-dependent nitrite production and apoptosis in beta cells. J. Biol. Chem. 275 (2000), p. 37672.

Ehrlich et al., 1999. L.C. Ehrlich, P.K. Peterson and S. Hu , Interleukin (IL)-1beta-mediated apoptosis of human astrocytes. NeuroReport 10 (1999), p. 1849.

Estevez et al., 1998. A.G. Estevez, N. Spear, S.M. Manuel, L. Barbeito, R. Radi and J.S. Beckman, Role of endogenous nitric oxide and peroxynitrite formation in the survival and death of motor neurons in culture. Prog. Brain Res. 118 (1998), p. 269. 
Eu et al., 2000. J.P. Eu, J. Sun, L. Xu, J.S. Stamler and G. Meissner, The skeletal muscle calcium release channel: coupled O2 sensor and NO signaling functions. Cell 102 (2000), p. 499.

Fadeel et al., 1998. B. Fadeel, A. Ahlin, J.I. Henter, S. Orrenius and M.B. Hampton, Involvement of caspases in neutrophil apoptosis: regulation by reactive oxygen species. Blood 92 (1998), p. 4808.

Faulkner and Fridovich, 1993. K. Faulkner and I. Fridovich , Luminol and lucigenin as detectors for O2. Free Radic. Biol. Med. 15 (1993), p. 447.

Fernandes and Cotter, 1994. R.S. Fernandes and T.G. Cotter , Apoptosis or necrosis: intracellular levels of glutathione influence mode of cell death. Biochem. Pharmacol. 48 (1994), p. 675.

Finkel, 2000. T. Finkel, Redox-dependent signal transduction. FEBS Lett. 476 (2000), p. 52.

Fiorucci et al., 2001. S. Fiorucci, A. Mencarelli, B. Palazzetti, P. Del Soldato, A. Morelli and L.J. Ignarro, An NO derivative of ursodeoxycholic acid protects against Fas-mediated liver injury by inhibiting caspase activity. Proc. Natl. Acad. Sci. U. S. A. 98 (2001), p. 2652.

Friesen et al., 1999. C. Friesen, S. Fulda and K.M. Debatin, Induction of CD95 ligand and apoptosis by doxorubicin is modulated by the redox state in chemosensitive- and drug-resistant tumor cells. Cell Death Differ. 6 (1999), p. 471.

Garvey et al., 1997. E.P. Garvey, J.A. Oplinger, E.S. Furfine, R.J. Kiff, F. Laszlo, B.J. Whittle and R.G. Knowles , $1400 \mathrm{~W}$ is a slow, tight binding, and highly selective inhibitor of inducible nitric-oxide synthase in vitro and in vivo. J. Biol. Chem. 272 (1997), p. 4959.

Genaro et al., 1995. A.M. Genaro, S. Hortelano, A. Alvarez, C. Martinez and L. Bosca, Splenic B lymphocyte programmed cell death is prevented by nitric oxide release through mechanisms involving sustained Bcl-2 levels. J. Clin. Invest. 95 (1995), p. 1884.

Ghibelli et al., 1998. L. Ghibelli, C. Fanelli, G. Rotilio, E. Lafavia, S. Coppola, C. Colussi, P. Civitareale and M.R. Ciriolo, Rescue of cells from apoptosis by inhibition of active GSH extrusion. FASEB J. 12 (1998), p. 479.

Gorman et al., 1997. A. Gorman, A. McGowan and T.G. Cotter, Role of peroxide and superoxide anion during tumour cell apoptosis. FEBS Lett. 404 (1997), p. 27.

Gorman et al., 1999. A.M. Gorman, B. Heavey, E. Creagh, T.G. Cotter and A. Samali , Antioxidantmediated inhibition of the heat shock response leads to apoptosis. FEBS Lett. 445 (1999), p. 98.

Green et al., 1982. L.C. Green, D.A. Wagner, J. Glogowski, P.L. Skipper, J.S. Wishnok and S.R. Tannenbaum , Analysis of nitrate, nitrite, and [15N]nitrate in biological fluids. Anal. Biochem. 126 (1982), p. 131.

Groves and Wang, 2000. J.T. Groves and C.C. Wang, Nitric oxide synthase: models and mechanisms. Curr. Opin. Chem. Biol. 4 (2000), p. 687.

Gyllenhammar, 1987. H. Gyllenhammar, Lucigenin chemiluminescence in the assessment of neutrophil superoxide production. J. Immunol. Methods 97 (1987), p. 209. 
Hampton and Orrenius, 1997. M.B. Hampton and S. Orrenius, Dual regulation of caspase activity by hydrogen peroxide: implications for apoptosis. FEBS Lett. 414 (1997), p. 552.

Hart and Dulhunty, 2000. J.D. Hart and A.F. Dulhunty, Nitric oxide activates or inhibits skeletal muscle ryanodine receptors depending on its concentration, membrane potential and ligand binding. J. Membr. Biol. 173 (2000), p. 227.

Hebestreit et al., 1998. H. Hebestreit, B. Dibbert, I. Balatti, D. Braun, A. Schapowal, K. Blaser and H.U. Simon, Disruption of fas receptor signaling by nitric oxide in eosinophils. J. Exp. Med. 187 (1998), p. 415.

Hockenbery et al., 1993. D.M. Hockenbery, Z.N. Oltvai, X.M. Yin, C.L. Milliman and S.J. Korsmeyer, Bcl-2 functions in an antioxidant pathway to prevent apoptosis. Cell 75 (1993), p. 241.

Iqbal and Whitney, 1991. J. Iqbal and P. Whitney, Use of cyanide and diethyldithiocarbamate in the assay of superoxide dismutases. Free Radic. Biol. Med. 10 (1991), p. 69.

Jacobson and Raff, 1995. M.D. Jacobson and M.C. Raff , Programmed cell death and Bcl-2 protection in very low oxygen. Nature 374 (1995), p. 814.

Joly et al., 1994. G.A. Joly, M. Ayres, F. Chelly and R.G. Kilbourn , Effects of NG-methyl-L-arginine, NG-nitro-L-arginine, and aminoguanidine on constitutive and inducible nitric oxide synthase in rat aorta. Biochem. Biophys. Res. Commun. 199 (1994), p. 147.

Kasahara et al., 1997. Y. Kasahara, K. Iwai, A. Yachie, K. Ohta, A. Konno, H. Seki, T. Miyawaki and N. Taniguchi , Involvement of reactive oxygen intermediates in spontaneous and CD95 (Fas/APO-1)mediated apoptosis of neutrophils. Blood 89 (1997), p. 1748.

Kaul et al., 1998. N. Kaul, J. Choi and H.J. Forman , Transmembrane redox signaling activates NFkappaB in macrophages. Free Radic. Biol. Med. 24 (1998), p. 202.

Kennedy et al., 1999. S.G. Kennedy, E.S. Kandel, T.K. Cross and N. Hay , Akt/Protein kinase B inhibits cell death by preventing the release of cytochrome $c$ from mitochondria. Mol. Cell. Biol. 19 (1999), p. 5800 .

Kerr et al., 1972. J.F. Kerr, A.H. Wyllie and A.R. Currie , Apoptosis: a basic biological phenomenon with wide-ranging implications in tissue kinetics. Br. J. Cancer 26 (1972), p. 239.

Kim et al., 1997a. Y.M. Kim, M.E. de Vera, S.C. Watkins and T.R. Billiar , Nitric oxide protects cultured rat hepatocytes from tumor necrosis factor-alpha-induced apoptosis by inducing heat shock protein 70 expression. J. Biol. Chem. 272 (1997), p. 1402.

Kim et al., 1997b. Y.M. Kim, R.V. Talanian and T.R. Billiar , Nitric oxide inhibits apoptosis by preventing increases in caspase-3-like activity via two distinct mechanisms. J. Biol. Chem. 272 (1997), p. 31138.

Kim et al., 1998a. Y.M. Kim, T.H. Kim, D.W. Seol, R.V. Talanian and T.R. Billiar , Nitric oxide suppression of apoptosis occurs in association with an inhibition of $\mathrm{Bcl}-2$ cleavage and cytochrome $\mathrm{C}$ release. J. Biol. Chem. 273 (1998), p. 31437. 
Kim et al., 1998b. Y.M. Kim, R.V. Talanian, J. Li and T.R. Billiar , Nitric oxide prevents IL-1beta and IFNgamma-inducing factor (IL-18) release from macrophages by inhibiting caspase-1 (IL-1betaconverting enzyme). J. Immunol. 161 (1998), p. 4122.

Kim et al., 1999. Y.M. Kim, H.T. Chung, S.S. Kim, J.A. Han, Y.M. Yoo, K.M. Kim, G.H. Lee, H.Y. Yun, A. Green, J. Li, R.L. Simmons and T.R. Billiar, Nitric oxide protects PC12 cells from serum deprivationinduced apoptosis by cGMP-dependent inhibition of caspase signaling. J. Neurosci. 19 (1999), p. 6740 .

Kim et al., 2000. Y.M. Kim, T.H. Kim, H.T. Chung, R.V. Talanian, X.M. Yin and T.R. Billiar, Nitric oxide prevents tumor necrosis factor alpha-induced rat hepatocyte apoptosis by the interruption of mitochondrial apoptotic signaling through S-nitrosylation of caspase-8. Hepatology 32 (2000), p. 770.

Kirkland and Franklin, 2001. R.A. Kirkland and J.L. Franklin , Evidence for redox regulation of cytochrome $\mathrm{c}$ release during programmed neuronal death: antioxidant effects of protein synthesis and caspase inhibition. J. Neurosci. 21 (2001), p. 1949.

Kluck et al., 1997. R.M. Kluck, E. Bossy-Wetzel, D.R. Green and D.D. Newmeyer, The release of cytochrome c from mitochondria: a primary site for $\mathrm{Bcl}-2$ regulation of apoptosis. Science 275 (1997), p. 1132.

Kojima et al., 1998. H. Kojima, N. Nakatsubo, K. Kikuchi, Y. Urano, T. Higuchi, J. Tanaka, Y. Kudo and T. Nagano, Direct evidence of NO production in rat hippocampus and cortex using a new fluorescent indicator: DAF-2 DA. NeuroReport 9 (1998), p. 3345.

Kooy et al., 1997. N.W. Kooy, J.A. Royall and H. Ischiropoulos, Oxidation of 2',7'-dichlorofluorescin by peroxynitrite. Free Radic. Res. 27 (1997), p. 245.

Kosower and Kosower, 1995. E.M. Kosower and N.S. Kosower, Bromobimane probes for thiols. Methods Enzymol. 251 (1995), p. 133.

Kotamraju et al., 2001. S. Kotamraju, N. Hogg, J. Joseph, L.K. Keefer and B. Kalyanaraman , Inhibition of oxidized low-density lipoprotein-induced apoptosis in endothelial cells by nitric oxide: peroxyl radical scavenging as an antiapoptotic mechanism. J. Biol. Chem. 1 (2001), p. 1.

Leist et al., 1999a. M. Leist, B. Single, H. Naumann, E. Fava, B. Simon, S. Kuhnle and P. Nicotera, Inhibition of mitochondrial ATP generation by nitric oxide switches apoptosis to necrosis. Exp. Cell Res. 249 (1999), p. 396.

Leist et al., 1999b. M. Leist, B. Single, H. Naumann, E. Fava, B. Simon, S. Kuhnle and P. Nicotera, Nitric oxide inhibits execution of apoptosis at two distinct ATP-dependent steps upstream and downstream of mitochondrial cytochrome c release. Biochem. Biophys. Res. Commun. 258 (1999), p. 215.

Lennon et al., 1991. S.V. Lennon, S.J. Martin and T.G. Cotter, Dose-dependent induction of apoptosis in human tumour cell lines by widely diverging stimuli. Cell Prolif. 24 (1991), p. 203.

Li and Billiar, 1999. J. Li and T.R. Billiar , The anti-apoptotic actions of nitric oxide in hepatocytes. Cell Death Differ. 6 (1999), p. 952. 
Li et al., 1997a. J. Li, T.R. Billiar, R.V. Talanian and Y.M. Kim , Nitric oxide reversibly inhibits seven members of the caspase family via S-nitrosylation. Biochem. Biophys. Res. Commun. 240 (1997), p. 419.

Li et al., 1997b. Y. Li, P. Maher and D. Schubert, Requirement for cGMP in nerve cell death caused by glutathione depletion. J. Cell Biol. 139 (1997), p. 1317.

Li et al., 1998. Y. Li, H. Zhu, P. Kuppusamy, V. Roubaud, J.L. Zweier and M.A. Trush, Validation of lucigenin (bis-N-methylacridinium) as a chemilumigenic probe for detecting superoxide anion radical production by enzymatic and cellular systems. J. Biol. Chem. 273 (1998), p. 2015.

Li et al., 2000. J. Li, S. Yang and T.R. Billiar , Cyclic nucleotides suppress tumor necrosis factor alphamediated apoptosis by inhibiting caspase activation and cytochrome c release in primary hepatocytes via a mechanism independent of Akt activation. J. Biol. Chem. 275 (2000), p. 13026.

Lieberthal et al., 1998. W. Lieberthal, V. Triaca, J.S. Koh, P.J. Pagano and J.S. Levine, Role of superoxide in apoptosis induced by growth factor withdrawal. Am. J. Physiol. 275 (1998), p. F691.

Lin et al., 1995. K.T. Lin, J.Y. Xue, M. Nomen, B. Spur and P.Y. Wong, Peroxynitrite-induced apoptosis in HL-60 cells. J. Biol. Chem. 270 (1995), p. 16487.

Liochev and Fridovich, 1997. S.I. Liochev and I. Fridovich , Lucigenin (bis-N-methylacridinium) as a mediator of superoxide anion production. Arch. Biochem. Biophys. 337 (1997), p. 115.

Liochev and Fridovich, 1998. S.I. Liochev and I. Fridovich , Lucigenin as mediator of superoxide production: revisited. Free Radic. Biol. Med. 25 (1998), p. 926.

Lipton et al., 1998. S.A. Lipton, P.V. Rayudu, Y.B. Choi, N.J. Sucher and H.S. Chen, Redox modulation of the NMDA receptor by NO-related species. Prog. Brain Res. 118 (1998), p. 73.

Littauer and de Groot, 1992. A. Littauer and H. de Groot, Release of reactive oxygen by hepatocytes on reoxygenation: three phases and role of mitochondria. Am. J. Physiol. 262 (1992), p. G1015.

Liu and Jan, 2000. F. Liu and K.Y. Jan , DNA damage in arsenite- and cadmium-treated bovine aortic endothelial cells. Free Radic. Biol. Med. 28 (2000), p. 55.

Lledias et al., 1998. F. Lledias, P. Rangel and W. Hansberg, Oxidation of catalase by singlet oxygen. J. Biol. Chem. 273 (1998), p. 10630.

Lopez-Collazo et al., 1997. E. Lopez-Collazo, J. Mateo, M.T. Miras-Portugal and L. Bosca, Requirement of nitric oxide and calcium mobilization for the induction of apoptosis in adrenal vascular endothelial cells. FEBS Lett. 413 (1997), p. 124.

Lundqvist-Gustafsson and Bengtsson, 1999. H. Lundqvist-Gustafsson and T. Bengtsson , Activation of the granule pool of the NADPH oxidase accelerates apoptosis in human neutrophils. J. Leukoc. Biol. 65 (1999), p. 196.

Mannick et al., 1997. J.B. Mannick, X.Q. Miao and J.S. Stamler, Nitric oxide inhibits Fas-induced apoptosis. J. Biol. Chem. 272 (1997), p. 24125. 
Mannick et al., 1999. J.B. Mannick, A. Hausladen, L. Liu, D.T. Hess, M. Zeng, Q.X. Miao, L.S. Kane, A.J. Gow and J.S. Stamler, Fas-induced caspase denitrosylation. Science 284 (1999), p. 651.

Marin et al., 1996. M.C. Marin, A. Fernandez, R.J. Bick, S. Brisbay, L.M. Buja, M. Snuggs, D.J. McConkey, A.C. von Eschenbach, M.J. Keating and T.J. McDonnell , Apoptosis suppression by bcl-2 is correlated with the regulation of nuclear and cytosolic Ca2+. Oncogene 12 (1996), p. 2259.

Marzinzig et al., 1997. M. Marzinzig, A.K. Nussler, J. Stadler, E. Marzinzig, W. Barthlen, N.C. Nussler, H.G. Beger, S.M. Morris, Jr. and U.B. Bruckner, Improved methods to measure end products of nitric oxide in biological fluids: nitrite, nitrate, and S-nitrosothiols. Nitric Oxide 1 (1997), p. 177.

Mates et al., 1999. J.M. Mates, C. Perez-Gomez and I. Nunez de Castro, Antioxidant enzymes and human diseases. Clin. Biochem. 32 (1999), p. 595.

McCullough et al., 2001. K.D. McCullough, J.L. Martindale, L.O. Klotz, T.Y. Aw and N.J. Holbrook, Gadd153 sensitizes cells to endoplasmic reticulum stress by down-regulating $\mathrm{Bcl} 2$ and perturbing the cellular redox state. Mol. Cell. Biol. 21 (2001), p. 1249.

McGowan et al., 1996. A.J. McGowan, R.S. Fernandes, A. Samali and T.G. Cotter , Anti-oxidants and apoptosis. Biochem. Soc. Trans. 24 (1996), p. 229.

Melino et al., 1997. G. Melino, F. Bernassola, R.A. Knight, M.T. Corasaniti, G. Nistico and A. FinazziAgro, S-nitrosylation regulates apoptosis. Nature 388 (1997), p. 432.

Mellqvist et al., 2000. U.H. Mellqvist, M. Hansson, M. Brune, C. Dahlgren, S. Hermodsson and K. Hellstrand, Natural killer cell dysfunction and apoptosis induced by chronic myelogenous leukemia cells: role of reactive oxygen species and regulation by histamine. Blood 96 (2000), p. 1961.

Michetti et al., 1995. M. Michetti, F. Salamino, E. Melloni and S. Pontremoli , Reversible inactivation of calpain isoforms by nitric oxide. Biochem. Biophys. Res. Commun. 207 (1995), p. 1009.

Michiels et al., 1994. C. Michiels, M. Raes, O. Toussaint and J. Remacle , Importance of Seglutathione peroxidase, catalase, and $\mathrm{Cu} / \mathrm{Zn}-\mathrm{SOD}$ for cell survival against oxidative stress. Free Radic. Biol. Med. 17 (1994), p. 235.

Minkenberg and Ferber, 1984. I. Minkenberg and E. Ferber , Lucigenin-dependent chemiluminescence as a new assay for $\mathrm{NAD}(\mathrm{P}) \mathrm{H}$-oxidase activity in particulate fractions of human polymorphonuclear leukocytes. J. Immunol. Methods 71 (1984), p. 61.

Mirkovic et al., 1997. N. Mirkovic, D.W. Voehringer, M.D. Story, D.J. McConkey, T.J. McDonnell and R.E. Meyn , Resistance to radiation-induced apoptosis in Bcl-2-expressing cells is reversed by depleting cellular thiols. Oncogene 15 (1997), p. 1461.

Misso et al., 2000. N.L. Misso, C.D. Peacock, D.N. Watkins and P.J. Thompson, Nitrite generation and antioxidant effects during neutrophil apoptosis. Free Radic. Biol. Med. 28 (2000), p. 934.

Mohr et al., 1997. S. Mohr, B. Zech, E.G. Lapetina and B. Brune , Inhibition of caspase-3 by Snitrosation and oxidation caused by nitric oxide. Biochem. Biophys. Res. Commun. 238 (1997), p. 387. 
Moore and Bland-Ward, 1996. P.K. Moore and P.A. Bland-Ward, 7-nitroindazole: an inhibitor of nitric oxide synthase. Methods Enzymol. 268 (1996), p. 393.

Moore et al., 1994. W.M. Moore, R.K. Webber, G.M. Jerome, F.S. Tjoeng, T.P. Misko and M.G. Currie , -N6-(1-iminoethyl)lysine: a selective inhibitor of inducible nitric oxide synthase. J. Med. Chem. 37 (1994), p. 3886.

Morel and Barouki, 1999. Y. Morel and R. Barouki, Repression of gene expression by oxidative stress. Biochem. J. 342 Pt 3 (1999), p. 481.

Mueller, 2000. S. Mueller, Sensitive and nonenzymatic measurement of hydrogen peroxide in biological systems. Free Radic. Biol. Med. 29 (2000), p. 410.

Mueller and Arnhold, 1995. S. Mueller and J. Arnhold, Fast and sensitive chemiluminescence determination of $\mathrm{H}_{2} \mathrm{O}_{2}$ concentration in stimulated human neutrophils. J. Biolumin. Chemilumin. 10 (1995), p. 229.

Murphy et al., 1991. T.H. Murphy, M.J. De Long and J.T. Coyle, Enhanced NAD(P)H:quinone reductase activity prevents glutamate toxicity produced by oxidative stress. J. Neurochem. 56 (1991), p. 990.

Nakatsubo et al., 1998a. N. Nakatsubo, H. Kojima, K. Kikuchi, H. Nagoshi, Y. Hirata, D. Maeda, Y. Imai, T. Irimura and T. Nagano, Direct evidence of nitric oxide production from bovine aortic endothelial cells using new fluorescence indicators: diaminofluoresceins. FEBS Lett. 427 (1998), p. 263.

Nakatsubo et al., 1998b. N. Nakatsubo, H. Kojima, K. Sakurai, K. Kikuchi, H. Nagoshi, Y. Hirata, T. Akaike, H. Maeda, Y. Urano, T. Higuchi and T. Nagano, Improved nitric oxide detection using 2,3diaminonaphthalene and its application to the evaluation of novel nitric oxide synthase inhibitors. Biol. Pharm. Bull. 21 (1998), p. 1247.

Nathan, 1997. C. Nathan , Inducible nitric oxide synthase: what difference does it make?. J. Clin. Invest. 100 (1997), p. 2417.

Nguyen et al., 1999. N.S. Nguyen, F. Cottet-Maire, T.M. Buetler, A. Lo Russo, A.S. Krauskopf, J.M. Armstrong, A.E. Vickers, K. Mace and U.T. Ruegg, Metabolism-dependent stimulation of reactive oxygen species and DNA synthesis by cyclosporin A in rat smooth muscle cells. Free Radic. Biol. Med. 27 (1999), p. 1267.

Nishikawa et al., 1998. M. Nishikawa, E.F. Sato, T. Kuroki, K. Utsumi and M. Inoue, Macrophagederived nitric oxide induces apoptosis of rat hepatoma cells in vivo. Hepatology 28 (1998), p. 1474.

Nourooz-Zadeh, 1999. J. Nourooz-Zadeh , Ferrous ion oxidation in presence of xylenol orange for detection of lipid hydroperoxides in plasma. Methods Enzymol. 300 (1999), p. 58.

O'Donnell et al., 1993. B.V. O'Donnell, D.G. Tew, O.T. Jones and P.J. England, Studies on the inhibitory mechanism of iodonium compounds with special reference to neutrophil NADPH oxidase. Biochem. J. 290 (1993), p. 41. 
Oda et al., 1999. T. Oda, N. Sadakata, N. Komatsu and T. Muramatsu, Specific efflux of glutathione from the basolateral membrane domain in polarized MDCK cells during ricin-induced apoptosis. J. Biochem. (Tokyo) 126 (1999), p. 715.

Oishi and Machida, 1997. K. Oishi and K. Machida, Inhibition of neutrophil apoptosis by antioxidants in culture medium. Scand. J. Immunol. 45 (1997), p. 21.

Okuda et al., 1996. Y. Okuda, S. Sakoda, M. Shimaoka and T. Yanagihara, Nitric oxide induces apoptosis in mouse splenic T lymphocytes. Immunol. Lett. 52 (1996), p. 135.

Olken et al., 1994. N.M. Olken, Y. Osawa and M.A. Marletta, Characterization of the inactivation of nitric oxide synthase by NG-methyl-L-arginine: evidence for heme loss. Biochemistry 33 (1994), p. 14784.

Ottonello et al., 2001. L. Ottonello, G. Frumento, N. Arduino, P. Dapino, G. Tortolina and F. Dallegri , Immune complex stimulation of neutrophil apoptosis: investigating the involvement of oxidative and nonoxidative pathways. Free Radic. Biol. Med. 30 (2001), p. 161.

Packer et al., 1996. M.A. Packer, C.M. Porteous and M.P. Murphy, Superoxide production by mitochondria in the presence of nitric oxide forms peroxynitrite. Biochem. Mol. Biol. Int. 40 (1996), p. 527.

Porter and Janicke, 1999. A.G. Porter and R.U. Janicke , Emerging roles of caspase-3 in apoptosis. Cell Death Differ. 6 (1999), p. 99.

Putnam et al., 2000. C.D. Putnam, A.S. Arvai, Y. Bourne and J.A. Tainer , Active and inhibited human catalase structures: ligand and NADPH binding and catalytic mechanism. J. Mol. Biol. 296 (2000), p. 295.

Raha et al., 2000. S. Raha, G.E. McEachern, A.T. Myint and B.H. Robinson, Superoxides from mitochondrial complex III: the role of manganese superoxide dismutase. Free Radic. Biol. Med. 29 (2000), p. 170.

Rao et al., 1992. K.M. Rao, J. Padmanabhan, D.L. Kilby, H.J. Cohen, M.S. Currie and J.B. Weinberg, Flow cytometric analysis of nitric oxide production in human neutrophils using dichlorofluorescein diacetate in the presence of a calmodulin inhibitor. J. Leukoc. Biol. 51 (1992), p. 496.

Reed, 1990. D.J. Reed, Glutathione: toxicological implications. Annu. Rev. Pharmacol. Toxicol. 30 (1990), p. 603.

Rees et al., 1990. D.D. Rees, R.M. Palmer, R. Schulz, H.F. Hodson and S. Moncada, Characterization of three inhibitors of endothelial nitric oxide synthase in vitro and in vivo. Br. J. Pharmacol. 101 (1990), p. 746.

Rice et al., 1986. G.C. Rice, E.A. Bump, D.C. Shrieve, W. Lee and M. Kovacs, Quantitative analysis of cellular glutathione by flow cytometry utilizing monochlorobimane: some applications to radiation and drug resistance in vitro and in vivo. Cancer Res. 46 (1986), p. 6105. 
Rodriguez-Lopez et al., 2000. A.M. Rodriguez-Lopez, O. Flores, C. Martinez-Salgado, N. Eleno, J.M. Lopez-Novoa and M. Arevalo, Increased apoptosis susceptibility in mesangial cells from spontaneously hypertensive rats. Microvasc. Res. 59 (2000), p. 80.

Rossig et al., 1999. L. Rossig, B. Fichtlscherer, K. Breitschopf, J. Haendeler, A.M. Zeiher, A. Mulsch and S. Dimmeler , Nitric oxide inhibits caspase-3 by S-nitrosation in vivo. J. Biol. Chem. 274 (1999), p. 6823.

Rossig et al., 2000. L. Rossig, J. Haendeler, C. Hermann, P. Malchow, C. Urbich, A.M. Zeiher and S. Dimmeler, Nitric oxide down-regulates MKP-3 mRNA levels: involvement in endothelial cell protection from apoptosis. J. Biol. Chem. 275 (2000), p. 25502.

Royall and Ischiropoulos, 1993. J.A. Royall and H. Ischiropoulos, Evaluation of 2',7'-dichlorofluorescin and dihydrorhodamine 123 as fluorescent probes for intracellular $\mathrm{H}_{2} \mathrm{O}_{2}$ in cultured endothelial cells. Arch. Biochem. Biophys. 302 (1993), p. 348.

Rubbo et al., 1994. H. Rubbo, R. Radi, M. Trujillo, R. Telleri, B. Kalyanaraman, S. Barnes, M. Kirk and B.A. Freeman, Nitric oxide regulation of superoxide and peroxynitrite-dependent lipid peroxidation: formation of novel nitrogen-containing oxidized lipid derivatives. J. Biol. Chem. 269 (1994), p. 26066.

Saez et al., 1985. G.T. Saez, F.J. Romero and J. Vina , Effects of glutathione depletion on gluconeogenesis in isolated hepatocytes. Arch. Biochem. Biophys. 241 (1985), p. 75.

Schulz et al., 1999. K. Schulz, S. Kerber and M. Kelm, Reevaluation of the Griess method for determining NO/NO2- in aqueous and protein-containing samples. Nitric Oxide 3 (1999), p. 225.

Shacter, 2000. E. Shacter, Quantification and significance of protein oxidation in biological samples. Drug Metab. Rev. 32 (2000), p. 307.

Shen et al., 1998. Y.H. Shen, X.L. Wang and D.E. Wilcken, Nitric oxide induces and inhibits apoptosis through different pathways. FEBS Lett. 433 (1998), p. 125.

Shi et al., 2000. Z.Z. Shi, J. Osei-Frimpong, G. Kala, S.V. Kala, R.J. Barrios, G.M. Habib, D.J. Lukin, C.M. Danney, M.M. Matzuk and M.W. Lieberman, Glutathione synthesis is essential for mouse development but not for cell growth in culture. Proc. Natl. Acad. Sci. U. S. A. 97 (2000), p. 5101.

Shiba and Shimamoto, 1999. D. Shiba and N. Shimamoto, Attenuation of endogenous oxidative stress-induced cell death by cytochrome P450 inhibitors in primary cultures of rat hepatocytes. Free Radic. Biol. Med. 27 (1999), p. 1019.

Shimizu et al., 1995. S. Shimizu, Y. Eguchi, H. Kosaka, W. Kamiike, H. Matsuda and Y. Tsujimoto, Prevention of hypoxia-induced cell death by Bcl-2 and Bcl-xL. Nature 374 (1995), p. 811.

Slivka et al., 1987a. A. Slivka, C. Mytilineou and G. Cohen, Histochemical evaluation of glutathione in brain. Brain Res. 409 (1987), p. 275.

Slivka et al., 1987b. A. Slivka, M.B. Spina and G. Cohen, Reduced and oxidized glutathione in human and monkey brain. Neurosci. Lett. 74 (1987), p. 112. 
Stamler et al., 1992. J.S. Stamler, D.J. Singel and J. Loscalzo , Biochemistry of nitric oxide and its redox-activated forms. Science 258 (1992), p. 1898.

Stassi et al., 1997. G. Stassi, R. De Maria, G. Trucco, W. Rudert, R. Testi, A. Galluzzo, C. Giordano and $M$. Trucco, Nitric oxide primes pancreatic beta cells for Fas-mediated destruction in insulindependent diabetes mellitus. J. Exp. Med. 186 (1997), p. 1193.

Stuehr et al., 1991. D.J. Stuehr, O.A. Fasehun, N.S. Kwon, S.S. Gross, J.A. Gonzalez, R. Levi and C.F. Nathan , Inhibition of macrophage and endothelial cell nitric oxide synthase by diphenyleneiodonium and its analogs. FASEB J. 5 (1991), p. 98.

Sun and Chen, 1998. A.Y. Sun and Y.M. Chen , Oxidative stress and neurodegenerative disorders. J. Biomed. Sci. 5 (1998), p. 401.

Suschek et al., 1999. C.V. Suschek, V. Krischel, D. Bruch-Gerharz, D. Berendji, J. Krutmann, K.D. Kroncke and V. Kolb-Bachofen, Nitric oxide fully protects against UVA-induced apoptosis in tight correlation with Bcl-2 up-regulation. J. Biol. Chem. 274 (1999), p. 6130.

Susin et al., 1998. S.A. Susin, N. Zamzami and G. Kroemer, Mitochondria as regulators of apoptosis: doubt no more. Biochim. Biophys. Acta 1366 (1998), p. 151.

Susin et al., 1999. S.A. Susin, H.K. Lorenzo, N. Zamzami, I. Marzo, B.E. Snow, G.M. Brothers, J. Mangion, E. Jacotot, P. Costantini, M. Loeffler, N. Larochette, D.R. Goodlett, R. Aebersold, D.P. Siderovski, J.M. Penninger and G. Kroemer, Molecular characterization of mitochondrial apoptosisinducing factor. Nature 397 (1999), p. 441.

Suzuki et al., 1998. Y. Suzuki, Y. Ono and Y. Hirabayashi, Rapid and specific reactive oxygen species generation via NADPH oxidase activation during Fas-mediated apoptosis. FEBS Lett. 425 (1998), p. 209.

Tabuchi et al., 1994. A. Tabuchi, K. Sano, E. Oh, T. Tsuchiya and M. Tsuda, Modulation of AP-1 activity by nitric oxide (NO) in vitro: NO-mediated modulation of AP-1. FEBS Lett. 351 (1994), p. 123.

Tai et al., 1997. X.G. Tai, K. Toyo-oka, N. Yamamoto, Y. Yashiro, J. Mu, T. Hamaoka and H. Fujiwara, Expression of an inducible type of nitric oxide (NO) synthase in the thymus and involvement of NO in deletion of TCR-stimulated double-positive thymocytes. J. Immunol. 158 (1997), p. 4696.

Tammariello et al., 2000. S.P. Tammariello, M.T. Quinn and S. Estus, NADPH oxidase contributes directly to oxidative stress and apoptosis in nerve growth factor-deprived sympathetic neurons. J. Neurosci. 20 (2000), p. RC53.

Tatoyan and Giulivi, 1998. A. Tatoyan and C. Giulivi , Purification and characterization of a nitricoxide synthase from rat liver mitochondria. J. Biol. Chem. 273 (1998), p. 11044.

Terradez et al., 1993. P. Terradez, M. Asensi, M.C. Lasso de la Vega, I.R. Puertes, J. Vina and J.M. Estrela, Depletion of tumour glutathione in vivo by buthionine sulphoximine: modulation by the rate of cellular proliferation and inhibition of cancer growth. Biochem. J. 292 (1993), p. 477. 
Thornberry and Lazebnik, 1998. N.A. Thornberry and Y. Lazebnik , Caspases: enemies within. Science 281 (1998), p. 1312.

Tome et al., 2001. M.E. Tome, A.F. Baker, G. Powis, C.M. Payne and M.M. Briehl , Catalaseoverexpressing thymocytes are resistant to glucocorticoid-induced apoptosis and exhibit increased net tumor growth. Cancer Res. 61 (2001), p. 2766.

Tracey et al., 1990. W.R. Tracey, J. Linden, M.J. Peach and R.A. Johns, Comparison of spectrophotometric and biological assays for nitric oxide (NO) and endothelium-derived relaxing factor (EDRF): nonspecificity of the diazotization reaction for NO and failure to detect EDRF. J. Pharmacol. Exp. Ther. 252 (1990), p. 922.

Ubezio and Civoli, 1994. P. Ubezio and F. Civoli , Flow cytometric detection of hydrogen peroxide production induced by doxorubicin in cancer cells. Free Radic. Biol. Med. 16 (1994), p. 509.

van den Dobbelsteen et al., 1996. D.J. van den Dobbelsteen, C.S. Nobel, J. Schlegel, I.A. Cotgreave, S. Orrenius and A.F. Slater, Rapid and specific efflux of reduced glutathione during apoptosis induced by anti-Fas/APO-1 antibody. J. Biol. Chem. 271 (1996), p. 15420.

Veis et al., 1993. D.J. Veis, C.M. Sorenson, J.R. Shutter and S.J. Korsmeyer , Bcl-2-deficient mice demonstrate fulminant lymphoid apoptosis, polycystic kidneys, and hypopigmented hair. Cell 75 (1993), p. 229.

Venkataraman et al., 2000. S. Venkataraman, S.M. Martin, F.Q. Schafer and G.R. Buettner, Detailed methods for the quantification of nitric oxide in aqueous solutions using either an oxygen monitor or EPR. Free Radic. Biol. Med. 29 (2000), p. 580.

Vento et al., 2000. R. Vento, N. D'Alessandro, M. Giuliano, M. Lauricella, M. Carabillo and G. Tesoriere, Induction of apoptosis by arachidonic acid in human retinoblastoma Y79 cells: involvement of oxidative stress. Exp. Eye Res. 70 (2000), p. 503.

Voehringer et al., 1998. D.W. Voehringer, D.J. McConkey, T.J. McDonnell, S. Brisbay and R.E. Meyn, $\mathrm{Bcl}-2$ expression causes redistribution of glutathione to the nucleus. Proc. Natl. Acad. Sci. U. S. A. 95 (1998), p. 2956.

Voehringer et al., 2000. D.W. Voehringer, D.L. Hirschberg, J. Xiao, Q. Lu, M. Roederer, C.B. Lock, L.A. Herzenberg and L. Steinman, Gene microarray identification of redox and mitochondrial elements that control resistance or sensitivity to apoptosis. Proc. Natl. Acad. Sci. U. S. A. 97 (2000), p. 2680.

Wei et al., 2000. T. Wei, C. Chen, J. Hou, W. Xin and A. Mori, Nitric oxide induces oxidative stress and apoptosis in neuronal cells. Biochim. Biophys. Acta 1498 (2000), p. 72.

Williams et al., 1998. M.S. Williams, S. Noguchi, P.A. Henkart and Y. Osawa, Nitric oxide synthase plays a signaling role in TCR-triggered apoptotic death. J. Immunol. 161 (1998), p. 6526.

Wolfe et al., 1994. J.T. Wolfe, D. Ross and G.M. Cohen, A role for metals and free radicals in the induction of apoptosis in thymocytes. FEBS Lett. 352 (1994), p. 58. 
Woo et al., 2000. C.H. Woo, Y.W. Eom, M.H. Yoo, H.J. You, H.J. Han, W.K. Song, Y.J. Yoo, J.S. Chun and J.H. Kim , Tumor necrosis factor-alpha generates reactive oxygen species via a cytosolic phospholipase A2-linked cascade. J. Biol. Chem. 275 (2000), p. 32357.

Wullner et al., 1996. U. Wullner, P.A. Loschmann, J.B. Schulz, A. Schmid, R. Dringen, F. Eblen, L. Turski and T. Klockgether, Glutathione depletion potentiates MPTP and MPP+ toxicity in nigral dopaminergic neurones. NeuroReport 7 (1996), p. 921.

Xu and Thornalley, 2001. K. Xu and P.J. Thornalley, Involvement of glutathione metabolism in the cytotoxicity of the phenethyl isothiocyanate and its cysteine conjugate to human leukaemia cells in vitro. Biochem. Pharmacol. 61 (2001), p. 165.

Yang et al., 1997. J. Yang, X. Liu, K. Bhalla, C.N. Kim, A.M. Ibrado, J. Cai, T.I. Peng, D.P. Jones and X. Wang , Prevention of apoptosis by $\mathrm{Bcl}-2$ : release of cytochrome $\mathrm{c}$ from mitochondria blocked. Science 275 (1997), p. 1129.

Zamzami et al., 1995. N. Zamzami, P. Marchetti, M. Castedo, C. Zanin, J.L. Vayssiere, P.X. Petit and G. Kroemer, Reduction in mitochondrial potential constitutes an early irreversible step of programmed lymphocyte death in vivo. J. Exp. Med. 181 (1995), p. 1661.

Zech et al., 1999. S.G. Zech, J. Kurreck, G. Renger, W. Lubitz and R. Bittl , Determination of the distance between $\mathrm{Y}(\mathrm{Z}) \mathrm{ox}$ * and QA-* in photosystem II by pulsed EPR spectroscopy on light-induced radical pairs. FEBS Lett. 442 (1999), p. 79.

Zhou et al., 2000. X. Zhou, S.A. Gordon, Y.M. Kim, R.A. Hoffman, Y. Chen, X.R. Zhang, R.L. Simmons and H.R. Ford, Nitric oxide induces thymocyte apoptosis via a caspase-1-dependent mechanism. J. Immunol. 165 (2000), p. 1252.

\section{FIGURE LEGENDS}

Fig. 1. Intracellular sources of ROS and principle defence mechanisms. Major sources of ROS production include the mitochondria, endoplasmic reticulum, plasma membrane and cytosol. The mitochondria generate $\mathrm{O}_{2}^{-}$during respiration, which is converted to $\mathrm{H}_{2} \mathrm{O}_{2}$ by Mn-SOD. In the cytosol, $\mathrm{O}^{-}$is converted to $\mathrm{H}_{2} \mathrm{O}_{2}$ by $\mathrm{Cu}, \mathrm{Zn}-\mathrm{SOD}$. The two major defence systems against $\mathrm{H}_{2} \mathrm{O}_{2}$ are the GSH redox cycle present in both the cytosol and mitochondria and catalase present only in the peroxisome fraction. Other sources of $\mathrm{O}_{2}^{-}$include the enzymes xanthine oxidase in the cytosol, NADPH oxidase in the membrane and cytochrome P450 in the ER. Bcl-2 can function as an antioxidant in some apoptotic systems through inducing the relocalisation of GSH to the nucleus. NO can be produced in the cytosol by nNOS, eNOS and iNOS or in the mitochondria by mtNOS.

Additionally, TNF $\alpha$ can induce NOS activation, resulting in the generation of nitric oxide. NO2 can react with membrane lipids and can also cause mutations in DNA. In addition, ONOO- can induce lipid peroxidation. Vitamin $E$ ( $\gamma$-tocopherol) is the main membrane antioxidant and is effective in inhibiting peroxynitrite oxidation of lipids and can also detoxify NO2 (Cooney and Christen). For more details, see text. 
Fig. 2. Schematic diagram illustrating the major subunits of the electron transport chain (ETC) and sites of $\mathrm{O}^{-}$production. Electrons enter the ETC at either complex I (NADH-ubiquinone oxidoreductase) or complex II (succinate dehydrogenase) following the oxidation of NADH and succinate, respectively. Ubiquinone is a lipid-soluble electron carrier and carries the electrons from complex I and complex II to complex III (ubiquinol-cytochrome c oxidoreductase). Superoxide ( $\left.\mathrm{O}^{-}{ }^{-}\right)$ can be produced at both complex I and complex III. It is believed that semiquinone formation at both complex I and complex III results in the production of $\mathrm{O}_{2}^{-}$. The inhibitors rotenone and myxathiazol inhibit electron transport at complex I and complex III of the ETC, respectively. These inhibitors can be used to prevent increases in superoxide produced by the mitochondria.

Fig. 3. Schematic model of NO regulation of cell death. NO can regulate cell death through cGMPdependent and CGMP-independent mechanisms. Activation of GC by NO results in the production of cGMP, which can regulate apoptosis through modulation of ion channels or activation of protein kinases such as Akt. cGMP-independent mechanisms are largely mediated through S-nitrosylation reactions. Proteins that have been reported to be S-nitrosylated include several members of the caspase family, tissue transglutamase, the two cysteine-transcription factors NF kappa B and AP-1, the $G$ protein Ras, several ion channels including the NMDA receptor and complex 1 of the electron transport chain.

Fig. 4. (A) Mechanism of action of DCFH-DA. DCFH-DA, a cell permeable, nonfluorescent precursor of DCF can be used as an intracellular probe for oxidative stress. Intracellular esterases cleave DCFH-DA at the two ester bonds, producing a relatively polar and cell membrane-impermeable product, H2DCF. This nonfluorescent molecule accumulates intracellularly and subsequent oxidation by hydrogen peroxide (or peroxynitrite) yields the highly fluorescent product DCF. The redox state of the sample can be monitored by detecting the increase in fluorescence. Various inhibitors can be used to elucidate the source of the oxidative stress. See text for more details. (B) Flow cytometric detection of oxidative stress using DCFH-DA. DCFH-DA detects oxidative stress in DU145 cells by treating with $40 \mu \mathrm{M}$ hydrogen peroxide for $10 \mathrm{~min}$ and $1 \mu \mathrm{M}$ anisomycin for $6 \mathrm{~h}$. Hydrogen peroxide is well known to induce oxidative stress in cells. Anisomycin is believed to activate the stress kinases through the generation of ROS. Increased fluorescence in the FL-1 channel indicates increased levels of oxidative stress. 
Figure 1
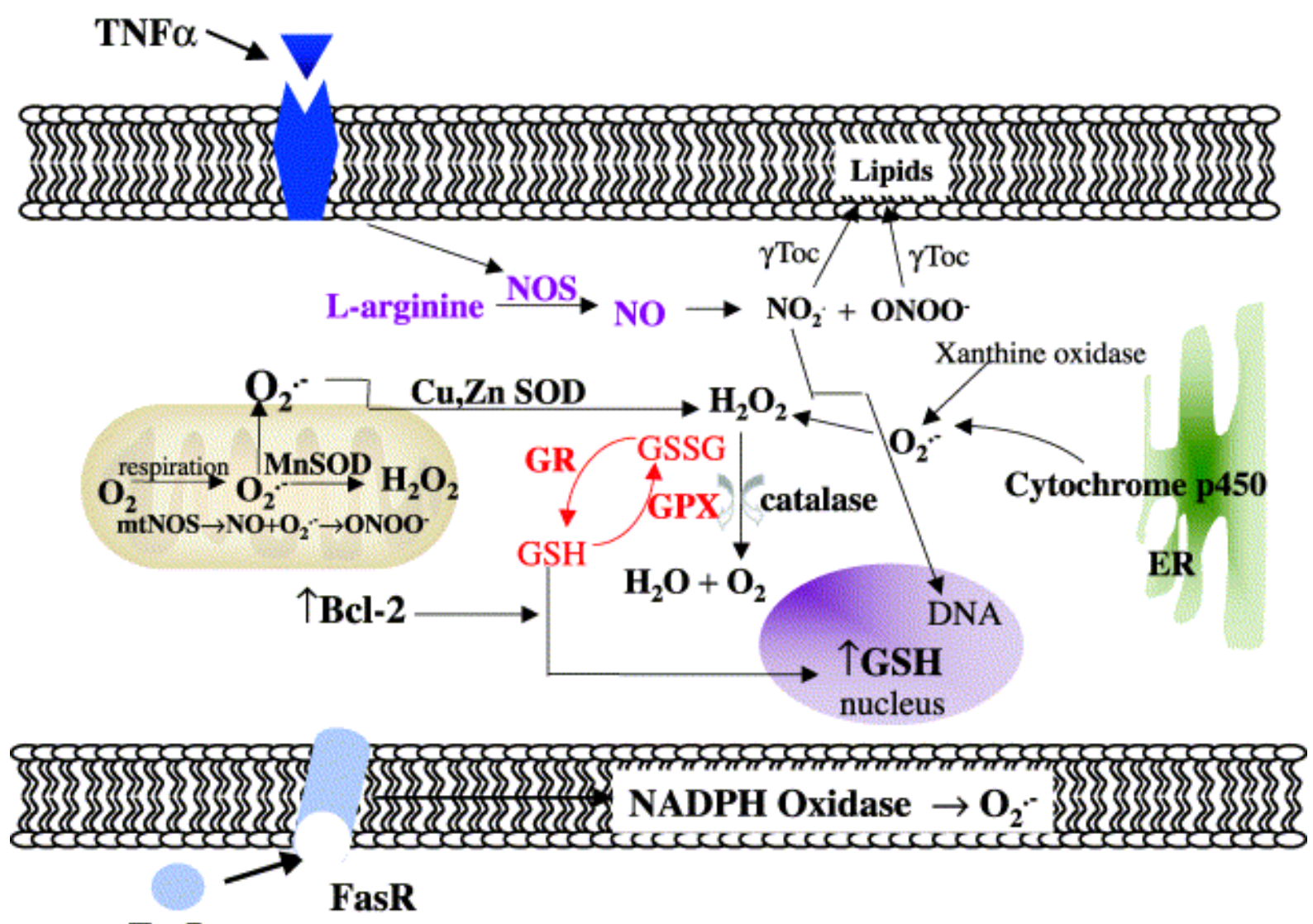

FasL 


\section{Figure 2}

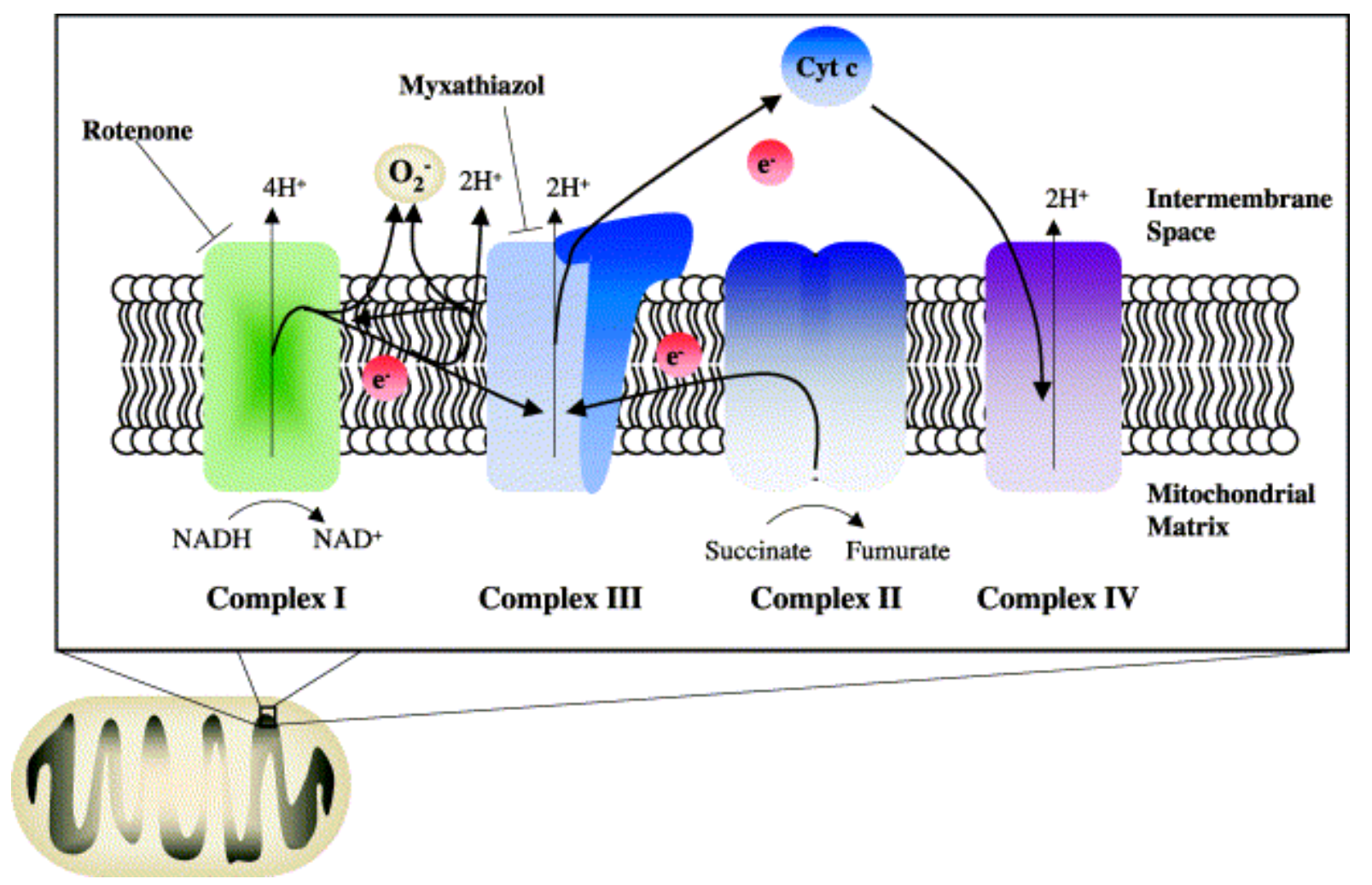


Figure 3

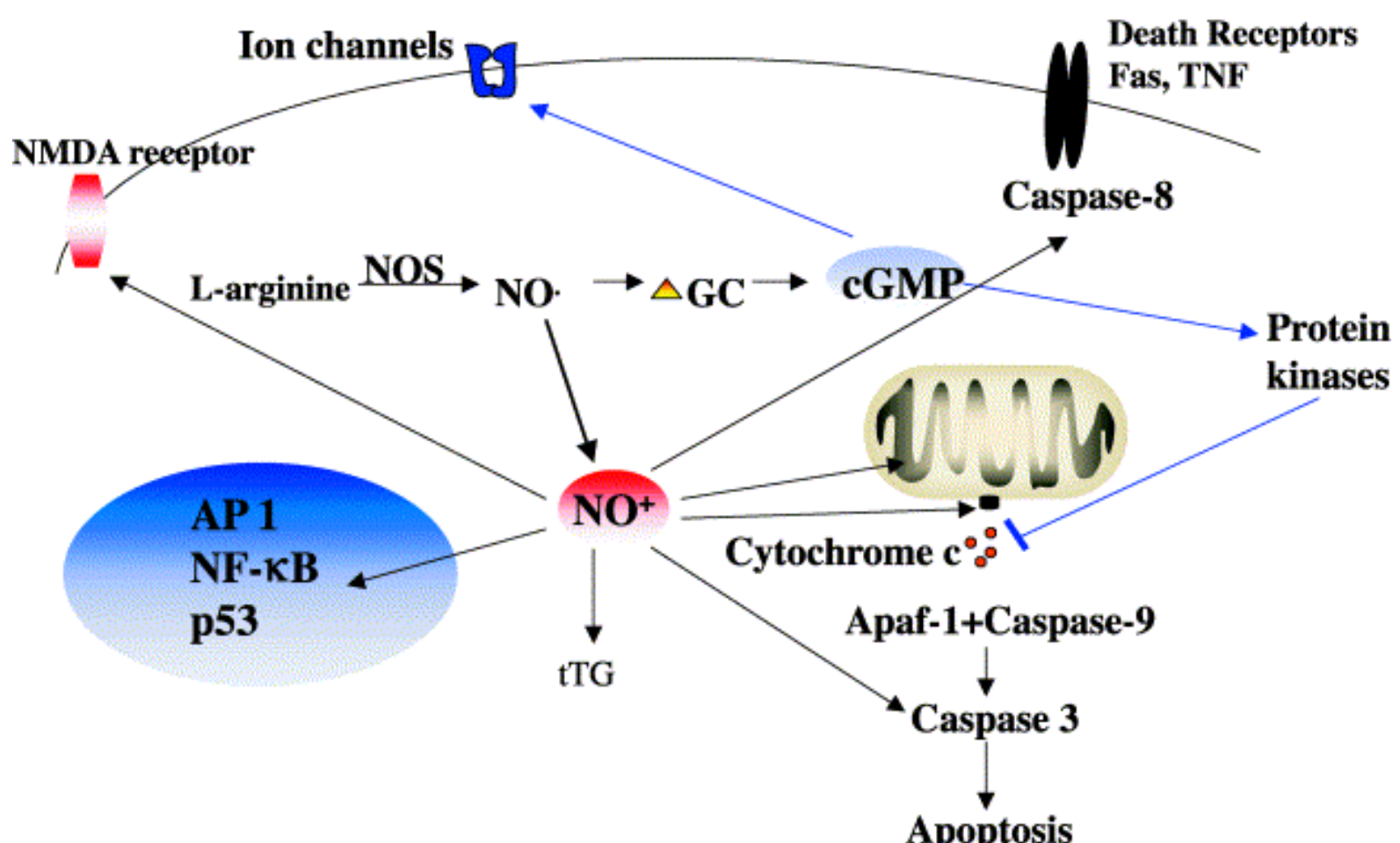


Figure $4 \mathrm{~A}$

A

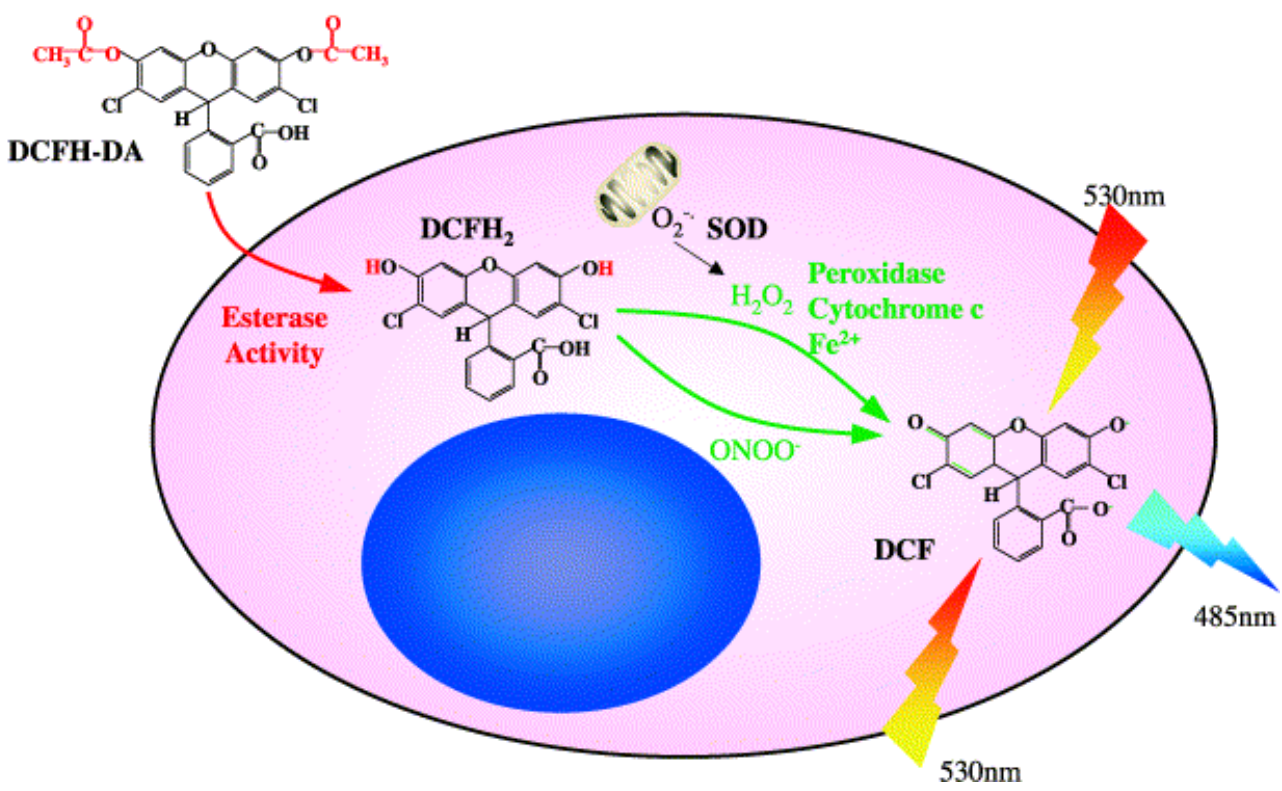

Figure 4B

B
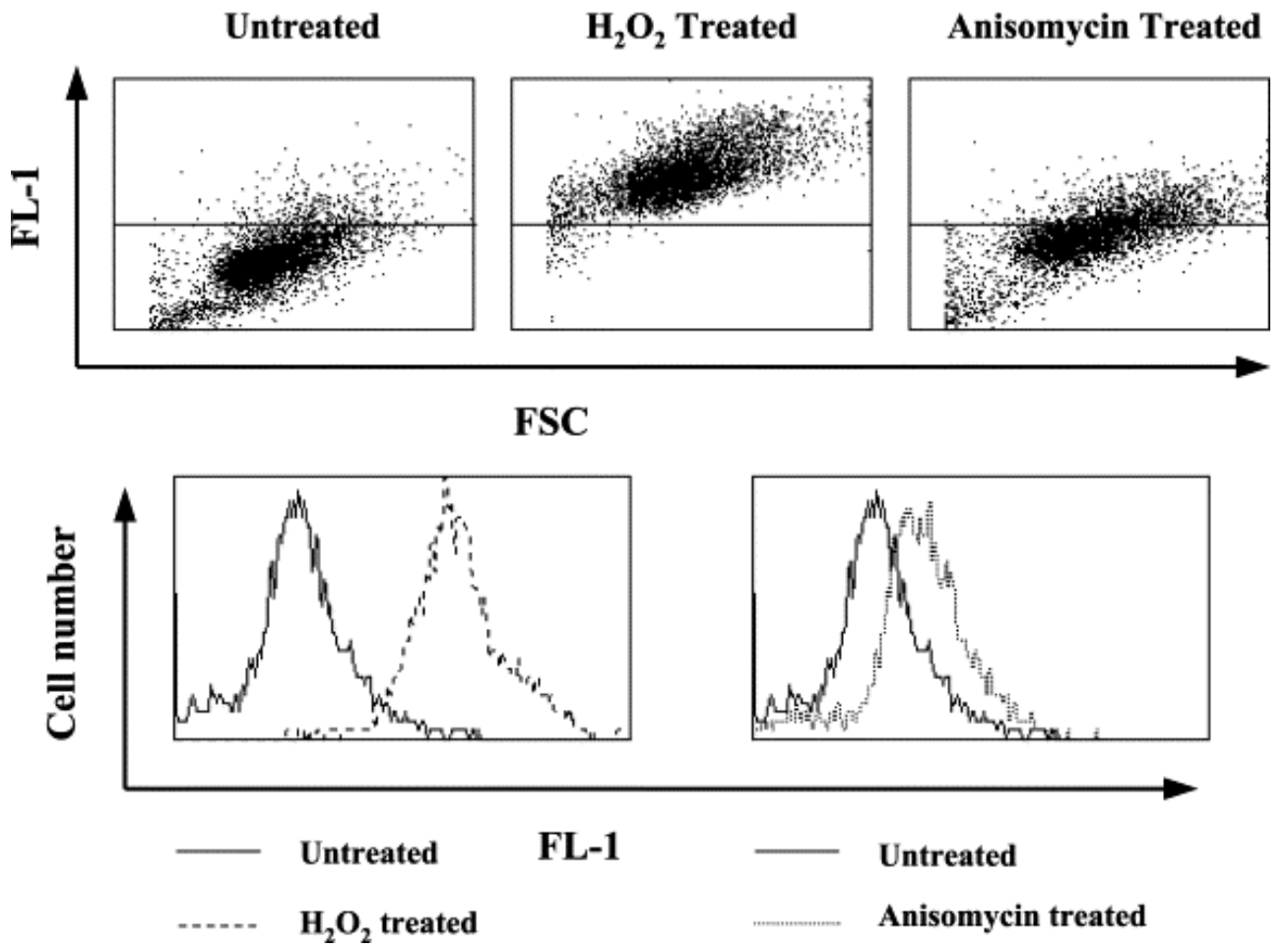